\title{
LncRNA NEAT1 enhances the resistance of anaplastic thyroid carcinoma cells to cisplatin by sponging miR-9-5p and regulating SPAG9 expression
}

\author{
PEI YAN, ZIJIE SU, ZHENHUA ZHANG and TENG GAO \\ Department of Thyroid Surgery, Henan Provincial People's Hospital, Zhengzhou, Henan 450000, P.R. China
}

Received November 22, 2018; Accepted June 24, 2019

DOI: $10.3892 /$ ijo.2019.4868

\begin{abstract}
Anaplastic thyroid carcinoma (ATC) has a poor prognosis due to its resistance to all conventional treatments. The long non-coding RNA (lncRNA) nuclear paraspeckle assembly transcript 1 (NEAT1) serves a critical role in cancer chemoresistance; however, whether NEAT1 is associated with chemoresistance of ATC remains unclear. In the present study, reverse transcription-quantitative PCR assays were performed to detect the expression levels of NEAT1, microRNA (miR)-9-5p and sperm-associated antigen 9 (SPAG9). Western blot analysis was conducted to assess the protein expression levels of p62, microtubule-associated proteins 1A/1B light chain 3B and SPAG9. Cell proliferation was detected using the Cell Counting kit- 8 assay, and cell apoptosis was determined by flow cytometry. Dual-luciferase reporter and RNA immunoprecipitation assays were performed to verify the interaction between NEAT1 and miR-9-5p, or miR-9-5p and SPAG9. Furthermore, an animal model was used to investigate the regulatory effects of NEAT1 on cisplatin (DDP)-resistance in tumors in vivo. The present results demonstrated that NEAT1 was upregulated in ATC tissues and cell lines, and NEAT1 silencing resulted in decreased DDP-resistance of ATC cells. In addition, NEAT1 suppressed miR-9-5p expression by binding to miR-9-5p and SPAG9 was a direct target of miR-9-5p. miR-9-5p overexpression sensitized ATC cells to DDP. Notably, NEAT1 silencing exerted its inhibitory effect on DDP-resistance of ATC via the miR-9-5p/SPAG9 axis in vitro and in vivo. In conclusion, the present study demonstrated that NEAT1 silencing ameliorated DDP-resistance of ATC, at least in part by reducing miR-9-5p sponging and regulating SPAG5 expression; therefore, NEAT1 may be considered a potential therapeutic target of ATC.
\end{abstract}

Correspondence to: Mr. Zijie Su, Department of Thyroid Surgery, Henan Provincial People's Hospital, 7 Weiwu Road, Jinshui, Zhengzhou, Henan 450000, P.R. China

E-mail: victory03019@163.com

Key words: anaplastic thyroid carcinoma, nuclear paraspeckle assembly transcript 1 , microRNA-9-5p, sperm-associated antigen 9, cisplatin resistance

\section{Introduction}

Anaplastic thyroid carcinoma (ATC) is an undifferentiated and aggressive type of cancer, which accounts for 1-2\% of all thyroid carcinomas. Despite its rareness, ATC is associated with a high recurrence rate and is responsible for the majority of deaths caused by thyroid cancer (1). Current treatments for ATC are diverse, including surgery, radiotherapy and chemotherapy; however, due to the resistance of ATC to almost all conventional treatments, the prognosis of patients with ATC remains very poor (2). Therefore, a better understanding of the molecular mechanisms underlying chemoresistance in ATC is required for the treatment of patients with ATC.

Long non-coding RNAs (lncRNAs), which are defined as non-coding transcripts $>200$ nucleotides in length, are important regulators of a wide range of biological and cellular processes (3). The abnormal expression of lncRNAs is involved in the tumorigenesis, progression and chemoresistance of human cancer, including thyroid cancer (4). The lncRNA nuclear paraspeckle assembly transcript 1 (NEAT1) is a 4-kb lncRNA localized to the nucleus, which has been demonstrated to act as an oncogene involved in numerous types of human cancer (5-8). Accumulating evidence has suggested that NEAT1 serves a critical role in cancer chemoresistance, such as in osteosarcoma, ovarian cancer and leukemia (9-11). Furthermore, upregulation of NEAT1 contributes to the progression of thyroid carcinoma by sponging microRNA (miRNA/miR)-214 (12). Conversely, NEAT1 knockdown suppresses the progression of papillary thyroid cancer through the miR-129-5p/kallikrein-related peptidase 7 axis (13). However, whether NEAT1 is associated with the chemoresistance of ATC remains unclear.

miRNAs are an abundant class of small non-coding, single-stranded RNAs, 22 nucleotides long, which function as negative gene regulators by binding to the 3 'untranslated region (3'-UTR) of their mRNA-target (14). The competing endogenous RNA (ceRNA) hypothesis proposes that lncRNAs function as 'miRNA sponges' to protect target mRNAs from suppression by sequestering specific miRNAs (15). The ceRNA concept is involved in numerous physiopathological processes, including cell differentiation, pluripotency, and tumorigenesis and chemoresistance (16). The aim of the present study was to investigate the functional role and molecular mechanism of NEAT1 in DDP-resistant ATC. The present study confirmed 
that NEAT1 silencing resulted in decreased DDP-resistance in ATC in vitro and in vivo. Furthermore, NEAT1 functioned as a ceRNA of miR-9-5p, and sperm-associated antigen 9 (SPAG9) was a direct target of miR-9-5p. These findings indicated that NEAT1 silencing sensitized ATC cell lines to DDP by suppressing miR-9-5p sponging and regulating SPAG9 expression.

\section{Materials and methods}

Clinical specimens and cell culture. A total of 26 pairs of tumor tissues and adjacent non-tumor thyroid tissues were collected from patients with ATC at Henan Provincial People's Hospital between May 2015 and March 2016; written informed consent was provided by all patients. The basic characteristics of all volunteers are shown in Table I. No conventional treatments were conducted prior to specimen collection. All specimens were stored as $-80^{\circ} \mathrm{C}$ until RNA extraction. The present study was approved by the Institutional Ethics Review Board of Henan Provincial People's Hospital. A human normal thyroid cell line (Nthy-ori 3-1) and two ATC cell lines (SW1736 and 8505C) were purchased from BeNa Culture Collection, and 293 cells were obtained from American Type Culture Collection. The cells were maintained in DMEM supplemented with 10\% FBS and $1 \%$ penicillin/streptomycin (all Gibco; Thermo Fisher Scientific, Inc.) at $37^{\circ} \mathrm{C}$ in a humidified incubator containing $5 \% \mathrm{CO}_{2}$.

Cell transfection. NEAT1 and SPAG9 overexpression vectors (Vector-NEAT1 and Vector-SPAG9) were commercially synthesized by Guangzhou Ribobio Co., Ltd., and an empty vector (pcDNA3.1; Guangzhou Ribobio Co., Ltd.) was used as negative control. Briefly, ATC cells $\left(2 \times 10^{5}\right.$ cells/well) were transfected with $20 \mathrm{mM}$ small interfering RNA (siRNA) targeting NEAT1 (si-NEAT1; Guangzhou Ribobio Co., Ltd.) or non-targeting control siRNA (Scramble; Guangzhou Ribobio Co., Ltd.); $50 \mathrm{mM}$ mature miR-9-5p mimics (Guangzhou Ribobio Co., Ltd.) or negative control (miR-NC mimics); 50 mM miR-9-5p inhibitor (anti-miR-9-5p; Guangzhou Ribobio Co., Ltd.) or control anti-NC; or $10 \mathrm{ng}$ Vector-NEAT1/SPAG9 or empty vector using Lipofectamine ${ }^{\circledR} 2000$ (Invitrogen; Thermo Fisher Scientific, Inc.), according to the manufacturer's protocol. Transfection efficiency was confirmed by reverse transcription-quantitative PCR (RT-qPCR). Successful NEAT1 vector, SPAG9 vector and anti-miR-9-5p transfection is shown in Fig. S2. A total of $24 \mathrm{~h}$ post-transfection, cells with positive transfection were harvested for subsequent treatment and experiments. The following sequences were used for transfection: si-NEAT1, 5'-GCCAUCAGCUUUGAAUAA AUU-3'; Scramble siRNA, 5'-UUCUCCGAACGUGUCACG U-3'; miR-9-5p mimic, 5'-GGUUAUCUAGCUGUAUGA-3'; miR-NC mimic, 5'-UCACAACCUCCUAGAAAGAGU-3'; anti-miR-9-5p, 5'-AUACAGCUAGAUAACCAAAG-3' and anti-NC, 5'-GUGUAACACGUCUAUACGCCCA-3'.

$R T-q P C R$. RT-qPCR assays were performed to detect the expression levels of NEAT1, miR-9-5p and SPAG9. Briefly, total RNA was isolated from ATC tissues and cells using TRIzol $^{\circledR}$ reagent (Invitrogen; Thermo Fisher Scientific, Inc.), and was treated with RNase-free DNase I (Roche Diagnostics $\mathrm{GmbH})$. The quality and concentration of RNA extracts were assessed using a NanoDrop spectrophotometer (NanoDrop Technologies; Thermo Fisher Scientific, Inc.). For NEAT1 and SPAG9 mRNA detection, 500 ng RNA was reverse transcribed to cDNA using the iScript cDNA Synthesis kit (Bio-Rad Laboratories, Inc.), according to the manufacturer's protocol, after which, qPCR was performed on an IQ5 Multi-color RT-PCR Detection system (Bio-Rad Laboratories, Inc.) with SYBR Green PCR Master Mix (Applied Biosystems; Thermo Fisher Scientific, Inc.). GAPDH was used as an endogenous control. For miR-9-5p detection, TaqMan miRNA Reverse Transcription kit (Applied Biosystems; Thermo Fisher Scientific, Inc.) and Taqman MicroRNA Assay kit (Applied Biosystems; Thermo Fisher Scientific, Inc.) were used in line with the manufacturer's protocols, and miR-9-5p expression was normalized to the expression of U6. The amplification parameters for NEAT1, SPAG9 and miR-9-5p quantification were: Denaturation at $95^{\circ} \mathrm{C}$ for $10 \mathrm{~min}$, followed by 40 cycles of denaturation at $95^{\circ} \mathrm{C}$ for $30 \mathrm{sec}$, annealing at $60^{\circ} \mathrm{C}$ for $30 \mathrm{sec}$ and extension at $72^{\circ} \mathrm{C}$ for $1 \mathrm{~min}$. The relative expression levels of NEAT1, SPAG9 and miR-9-5p were calculated using the $2^{-\Delta \Delta C q}$ method (17). For RT-qPCR, the following primers were used: NEAT1, forward 5'-GTACGCGGGCAGACT AACAC-3', reverse 5'-TGCGTCTAGACACCACAACC-3'; SPAG9, forward 5'-ATGTCCATAATTATATGGAACATT TA-3', reverse 5'-TAAGTTGATGACCCATTATTAACCA-3'; GAPDH, forward 5'-TTGCCATCAATGACCCCTTCA-3', reverse 5'-CGCCCCACTTGATTTTGGA-3'; miR-9-5p, forward 5'-GTGCAGGGTCCGAGGT-3', reverse 5'-GCGCTC TTTGGTTATCTAGC-3'; and U6, forward 5'-GCTTCGGCA GCACATATACTAAAAT-3' and reverse 5'-CGCTTCACG AATTTGCGTGTCAT-3'.

Cell Counting kit-8 (CCK-8) assay. Cell proliferation was measured using the CCK-8 (Dojindo Molecular Technologies, Inc.), according to the manufacturer's protocol. Transfected cells $\left(2 \times 10^{3}\right.$ cells/well) were treated with or without $30 \mu \mathrm{g} / \mathrm{ml}$ DDP (Shanghai Aladdin Bio-Chem Technology Co., Ltd.) in 96-well plates. At the indicated time (0, 24, 48 and $72 \mathrm{~h}), 10 \mu \mathrm{l}$ CCK-8 solution was added to each well for $2 \mathrm{~h}$ at $37^{\circ} \mathrm{C}$, after which, absorbance at a wavelength of $450 \mathrm{~nm}$ was determined.

Flow cytometry. Cell apoptosis was assessed by flow cytometry using the Annexin V-FITC Apoptosis Detection kit (BD Biosciences). Briefly, transfected cells were harvested and washed with pre-cooled PBS (Invitrogen; Thermo Fisher Scientific, Inc.), then fixed with $70 \%$ cold ethanol on ice for $1 \mathrm{~h}$ at $4^{\circ} \mathrm{C}$. Subsequently, cells were resuspended in $500 \mu$ l Binding Buffer, and were then labeled with $5 \mu \mathrm{l}$ Annexin V-FITC and $10 \mu 1$ propidium iodide for $10 \mathrm{~min}$ in the dark at $37^{\circ} \mathrm{C}$. Finally, the samples were immediately analyzed using a FACScan flow cytometer (BD Biosciences) with Cell Quest software v6.0 (BD Biosciences).

Transwell assay. A total of $200 \mu 1$ serum-free DMEM containing transfected cells $\left(5 \times 10^{4}\right.$ cells/well $)$ was added to the upper chamber of 24-well Transwell plates with a Matrigel-coated membrane (pore size, $8 \mu \mathrm{m}$; Corning, Inc.), and $600 \mu \mathrm{l}$ growth medium containing 10\% FBS was added to the lower chamber of the plates. After $48 \mathrm{~h}$ at $37^{\circ} \mathrm{C}$, the invasive cells were stained with $0.1 \%$ crystal violet at $37^{\circ} \mathrm{C}$ for 
Table I. Association of NEAT1 expression with clinical characteristics of patients with anaplastic thyroid carcinoma.

\begin{tabular}{|c|c|c|c|c|}
\hline \multirow[b]{2}{*}{ Clinical feature } & \multirow[b]{2}{*}{$\mathrm{n}$} & \multicolumn{2}{|c|}{$\begin{array}{c}\text { NEAT1 } \\
\text { expression }\end{array}$} & \multirow[b]{2}{*}{ P-value } \\
\hline & & High & Low & \\
\hline Age, years & & & & 0.899 \\
\hline$\geq 60$ & 16 & 10 & 6 & \\
\hline$<60$ & 10 & 6 & 4 & \\
\hline Sex & & & & 0.420 \\
\hline Male & 8 & 4 & 4 & \\
\hline Female & 18 & 12 & 6 & \\
\hline TNM stage & & & & $0.008^{\mathrm{a}}$ \\
\hline IVA-B & 15 & 6 & 9 & \\
\hline IVC & 11 & 10 & 1 & \\
\hline Smoking status & & & & 0.769 \\
\hline Yes & 6 & 4 & 2 & \\
\hline No & 20 & 12 & 8 & \\
\hline Lymph node metastasis & & & & $0.024^{\mathrm{a}}$ \\
\hline N0 & 11 & 4 & 7 & \\
\hline N1 & 15 & 12 & 3 & \\
\hline
\end{tabular}

${ }^{\mathrm{a}} \mathrm{P}<0.05$, as determined using $\chi^{2}$ test. NEAT1, nuclear paraspeckle assembly transcript.

$15 \mathrm{~min}$. The images were captured and the number of invaded cells was counted under a microscope (x100 magnification; Leica DM 300; Leica Microsystems GmbH).

Western blot analysis. Total protein was obtained from treated cells using ice-cold lysis buffer (50 nM Tris- $\mathrm{HCl}$, $100 \mathrm{mM} \mathrm{NaCl}, 1 \mathrm{mM}$ EDTA, 1 mM EGTA, 1\% Triton X-100, $0.1 \mathrm{mM}$ phenylmethyl sulfonyl fluoride, $30 \mathrm{mM}$ sodium pyrophosphate; $\mathrm{pH}$ 7.4) containing a protease inhibitor cocktail (Sigma-Aldrich; Merck KGaA). Protein concentrations were measured using a Bicinchoninic Acid Protein Assay kit (Novagen; EMD Millipore). Equivalent amounts of protein $(50 \mu \mathrm{g})$ were separated by $10 \%$ SDS-PAGE and were then transferred onto nitrocellulose membranes (EMD Millipore). After blocking in 5\% nonfat milk for $1 \mathrm{~h}$ at room temperature, the membranes were incubated with primary antibodies for $1 \mathrm{~h}$ at room temperature, followed by incubation with horseradish peroxidase-conjugated anti-mouse or anti-rabbit immunoglobulin G (IgG; cat. no. ab6728 or ab6721; 1:2,000; Abcam) as secondary antibodies. The protein bands were visualized using an enhanced chemiluminescence (ECL) substrate kit (Bio-Rad Laboratories, Inc.) with the ECL western blotting system (Bio-Rad Laboratories, Inc.). The following primary antibodies were used: Anti-Bax (cat. no. ab32503; 1:2,000; Abcam), anti-Bcl-2 (cat. no. ab32124; 1:1,000; Abcam), anti-cleaved (C)-caspase 3 (cat. no. ab49822; 1:1,000; Abcam), anti-p62 (cat. no. ab56416; 1:1,000; Abcam), anti-microtubule-associated proteins 1A/1B light chain 3B (LC3B) (cat. no. ab168831; 1:500; Abcam), anti-SPAG9 (cat. no. ab12331; 1:1,000; Abcam) and anti-GAPDH (cat. no. ab8245; 1:1,000; Abcam).
Dual-luciferase reporter assay. Online software StarBase v.2.0 (starbase.sysu.edu.cn) was used to search for the directly interacting miRNAs of NEAT1. TargetScan 6.2 online software (www.targetscan.org/vert_71) was used to predict the targets of miRNAs. NEAT1 wild-type or mutant-type reporter vectors (NEAT1-wt or NEAT1-mut), and SPAG9 wild-type or mutant-type reporter vectors (SPAG9-wt or SPAG9-mut) constructed by Guangzhou Ribobio Co., Ltd., were cotransfected into cells $\left(5 \times 10^{4}\right.$ cells/well) together with $20 \mathrm{nM}$ miR-NC mimics or miR-9-5p mimics for $48 \mathrm{~h}$ at room temperature. A total of $48 \mathrm{~h}$ post-transfection, luciferase activity was analyzed using a Dual-luciferase Reporter Assay system (Promega Corporation), according to the manufacturer's protocol.

RNA immunoprecipitation (RIP) assay. RIP assay was performed to determine whether NEAT1 or SPAG9 was associated with miR-9-5p in RNA-induced silencing complex (RISC) using the Magna RIP ${ }^{\text {TM }}$ RNA-binding immunoprecipitation kit (EMD Millipore), according to the manufacturer's protocol. Briefly, cells were transfected with miR-9-5p mimics and lysed with lysis buffer containing a protease inhibitor cocktail (EMD Millipore). Argonaute2 (Ago2) is the core component of the RISC and serves a crucial role in the mature process of miRNAs (14). Therefore, cell lysates were incubated with magnetic beads and anti-Ago2 (cat. no. ab32381; 1:500; Abcam) or anti-IgG (ab172730; 1:100; Abcam) at $4^{\circ} \mathrm{C}$ for $24 \mathrm{~h}$. Finally, the beads were collected using a magnetic micro centrifuge tube rack at $3,000 \mathrm{xg}$ for $10 \mathrm{~min}$ at $4^{\circ} \mathrm{C}$ and digested with $1 \mu \mathrm{g} / \mathrm{ml}$ DNase (cat. no. M6101; Promega Corporation) and $50 \mu \mathrm{g} / \mathrm{ml}$ Proteinase K (cat. no. P6556; Sigma-Aldrich; Merck $\mathrm{KGaA}$ ) at $37^{\circ} \mathrm{C}$ for $10 \mathrm{~min}$, and NEAT1 or SPAG9 mRNA enrichment was measured by RT-qPCR.

RNA pull-down assay. To detect the endogenous interaction between NEAT1 and miR-9-5p in ATC cells, a RNA pull-down assay was performed. Biotinylated RNA was prepared using the Biotin 3'End DNA Labeling kit (Thermo Fisher Scientific, Inc.), according to the manufacturer's protocol. Biotinylated miR-9-5p mimics (bio-miR-9-5p; $20 \mathrm{nM}$ ) were transfected into ATC cells $\left(3 \times 10^{5}\right.$ cells/well $)$ at $37^{\circ} \mathrm{C}$ for $48 \mathrm{~h}$ using Lipofectamine ${ }^{\circledR} 2000$ (Invitrogen; Thermo Fisher Scientific, Inc.), and biotinylated miR-NC mimic (bio-miR-NC; $20 \mathrm{nM}$ ) was used as a negative control. After $48 \mathrm{~h}$, cells were lysed using ice-cold lysis buffer and the supernatant was collected. Subsequently, cell lysates were incubated with Dynabeads M-280 Streptavidin (BD Biosciences) to absorb bio-miR-9-5p at $4^{\circ} \mathrm{C}$ for $2 \mathrm{~h}$, forming bio-miRNA-lncRNA complexes. Finally, the complexes were collected by centrifugation at $3,000 \mathrm{x} \mathrm{g}$ for $10 \mathrm{~min}$ at $4^{\circ} \mathrm{C}$ and the relative enrichment of NEAT1 was assessed in bio-miRNA-lncRNA complexes by RT-qPCR.

Short hairpin RNA (shRNA)-mediated silencing of NEAT1. Lentiviral vectors expressing NEAT1-targeted shRNA (lenti-shNEAT1, 5'-GACCGUGGUUUGUUACUAU-3') or non-target control shRNA (lenti-Scramble, 5'-UUCUCCGAA CGUGUCACGU-3') were constructed using BLOCK-iT ${ }^{\mathrm{TM}}$ Lentiviral RNAi Expression System (cat. no. K494400; Invitrogen; Thermo Fisher Scientific, Inc.), according to the manufacturer's protocol. Lenti-shNEAT1 (10 nM) or 
lenti-Scramble $(10 \mathrm{nM})$ vectors were cotransfected into 293 cells $\left(1 \times 10^{6}\right.$ cells; American Type Culture Collection) using Lipofectamine ${ }^{\circledR} 2000$ (Invitrogen; Thermo Fisher Scientific, Inc.) together with psPAX2 and pMD2.G $(10 \mathrm{ng} / \mathrm{ml}$; Addgene) to generate lentiviral particles at $37^{\circ} \mathrm{C}$. After $48 \mathrm{~h}$, shRNA-expressing lentivirus particles were collected and used to infect ATC cell lines $\left(5 \times 10^{5}\right.$ cells/well) at a multiplicity of infection of 100:1. After $24 \mathrm{~h}$, cells were cultured in $1 \mu \mathrm{g} / \mathrm{ml}$ puromycin to select stable NEAT1-silenced ATC cells, and PT-qPCR was used to assess the expression of NEAT1.

In vivo assay. Male BALB/c mice (weight; 18-22 g; age, 6-8 weeks; $n=16$ ) were purchased from Hubei Research Center of Laboratory Animal. Mice were maintained under specific pathogen-free conditions at a constant temperature of $22 \pm 2^{\circ} \mathrm{C}$ and $60 \%$ humidity, under a 12 -h light/dark, and were fed a standard chow diet ad libitum for at least 1 week before experimentation. Approximately $5.0 \times 10^{6} \mathrm{SW} 1736$ or $8505 \mathrm{C}$ cells transfected with lenti-Scramble or lenti-shNEAT1 were subcutaneously injected into nude mice to develop xenografts $(n=8)$. At 3 days post-injection, PBS solution or DDP solution $(3 \mathrm{mg} / \mathrm{kg}$ ) was intravenously administered into in each mouse every 4 days. After 4 weeks, the mice were sacrificed and tumor tissues were removed, weighed and analyzed. All animal experiments were conducted according to the national standard of the care and use of laboratory animals, and the study was approved by the Committee of Animal Research of Henan Provincial People's Hospital.

Statistical analysis. All data were analyzed using SPSS 18.0 software (SPSS, Inc.) and are presented as the mean \pm standard deviation. Fold changes in tissue gene expression were analyzed using paired Student's t-test, and differences between two other groups were analyzed by unpaired Student's t-test. Multiple groups were compared by one-way ANOVA with an honestly significant difference-q test. Correlations between SPAG9 and NEAT1 or miR-9-5p were analyzed by Spearman's test. $\chi^{2}$ test was used to evaluate the association between NEAT1 expression and clinical characteristics of patients with ATC. $\mathrm{P}<0.05$ was considered to indicate a statistically significant difference. Each assay was performed independently at least three times.

\section{Results}

NEAT1 expression is upregulated in ATC tissues and cell lines. Initially, the present study analyzed NEAT1 expression in ATC tissues and adjacent normal thyroid tissues by RT-qPCR. The results revealed that NEAT1 was significantly upregulated in tumor tissues compared with in adjacent non-tumor tissues (Fig. 1A). In addition, the expression levels of NEAT1 were analyzed in ATC cell lines (SW1736 and 8505C) and in a human normal thyroid cell line (Nthy-ori 3-1). As shown in Fig. 1B, NEAT1 expression levels were highly elevated in ATC cell lines compared with in the normal control.

Association between NEAT1 expression and clinical characteristics. Subsequently, the association between NEAT1 expression and clinical characteristics was determined. As shown in Table I, NEAT1 expression was significantly associated with TNM stage (18) $(\mathrm{P}=0.008)$ and lymph node
A

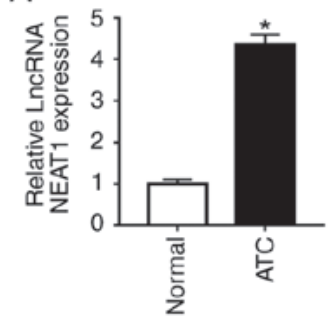

$\mathrm{B}$

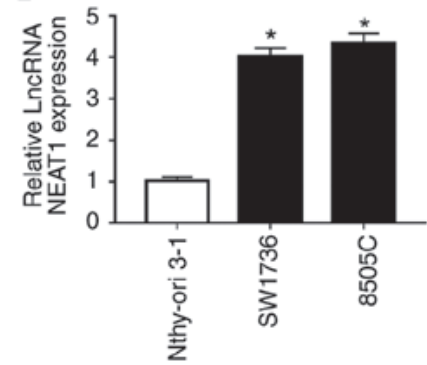

Figure 1. NEAT1 expression is upregulated in ATC tissues and cell lines. NEAT1 expression was assessed by reverse transcription-quantitative PCR in (A) 26 pairs of ATC and adjacent normal thyroid tissues, and (B) in two ATC cell lines (SW1736 and 8505C) and a human normal thyroid cell line (Nthy-ori 3-1). ${ }^{*} \mathrm{P}<0.05$ vs. normal tissues or Nthy-ori 3-1 cells. ATC, anaplastic thyroid carcinoma; lncRNA, long non-coding RNA; NEAT1, nuclear paraspeckle assembly transcript 1 .

metastasis $(\mathrm{P}=0.024)$. Conversely, other clinical characteristics were not associated with NEAT1 expression.

NEAT1 silencing reduces DDP-resistance of $S W 1736$ and $8505 \mathrm{C}$ cells. To explore the function of NEAT1 on DDP-resistance of ATC, loss-of-function experiments were performed by transfecting SW1736 and 8505C cells with si-NEAT1, followed by treatment with or without DDP. As shown in Fig. 2A, compared with in the Scramble siRNA group, transfection with si-NEAT1 resulted in a 57\% reduction in NEAT1 expression in SW1736 cells, and a $62 \%$ reduction in $8505 \mathrm{C}$ cells. Subsequent functional experiments revealed that NEAT1 silencing markedly suppressed cell proliferation and invasion, and promoted cell apoptosis compared with in the Scramble group (Fig. 2B and C; Fig. S1). Furthermore, western blot analysis revealed that NEAT1 silencing significantly inhibited Bcl-2 expression, and increased Bax and C-caspase 3 levels, supporting the hypothesis that NEAT1 silencing may promote cell apoptosis (Fig. 2D and E). The expression levels of LC3, an autophagosome membrane protein, and receptor protein p62 are widely acknowledged to reflect the activity of autophagy (19). Therefore, the expression levels of LC3-II/I and p62 were detected, in order to explore the role of NEAT1 in cell autophagy. The results demonstrated that NEAT1 silencing resulted in a decrease in p62 expression, and an increase in LC3-II/I, thus indicating that NEAT1 silencing may elevate autophagy in SW1736 and 8505C cells (Fig. 2F and G).

Notably, compared with in the si-NEAT1 or Scramble + DDP group, simultaneous NEAT1 silencing and DDP treatment in SW1736 and 8505C cells led to a more distinct inhibition of cell proliferation and a more obvious promotion of cell apoptosis (Fig. 2B-E). Furthermore, NEAT1 silencing in DDP-treated cells markedly promoted cell autophagy (Fig. 2F and G). These data indicated that NEAT1 silencing promoted ATC cell sensitivity to DDP.

NEAT1 binds to miR-9-5p and suppresses miR-9-5p expression. To further investigate the molecular mechanism by which NEAT1 affected the DDP-resistance of ATC cells, StarBase v.2.0 software was used to search for the directly interacting 
A

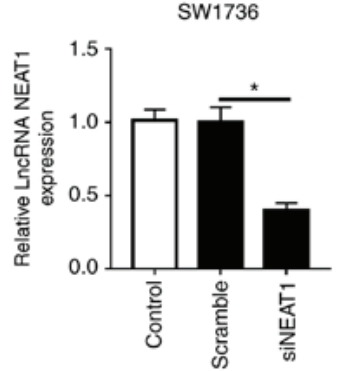

B

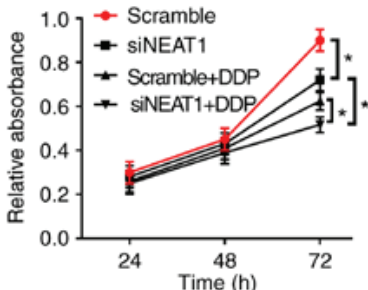

$8505 \mathrm{C}$

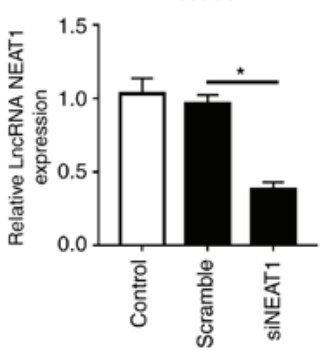

85050
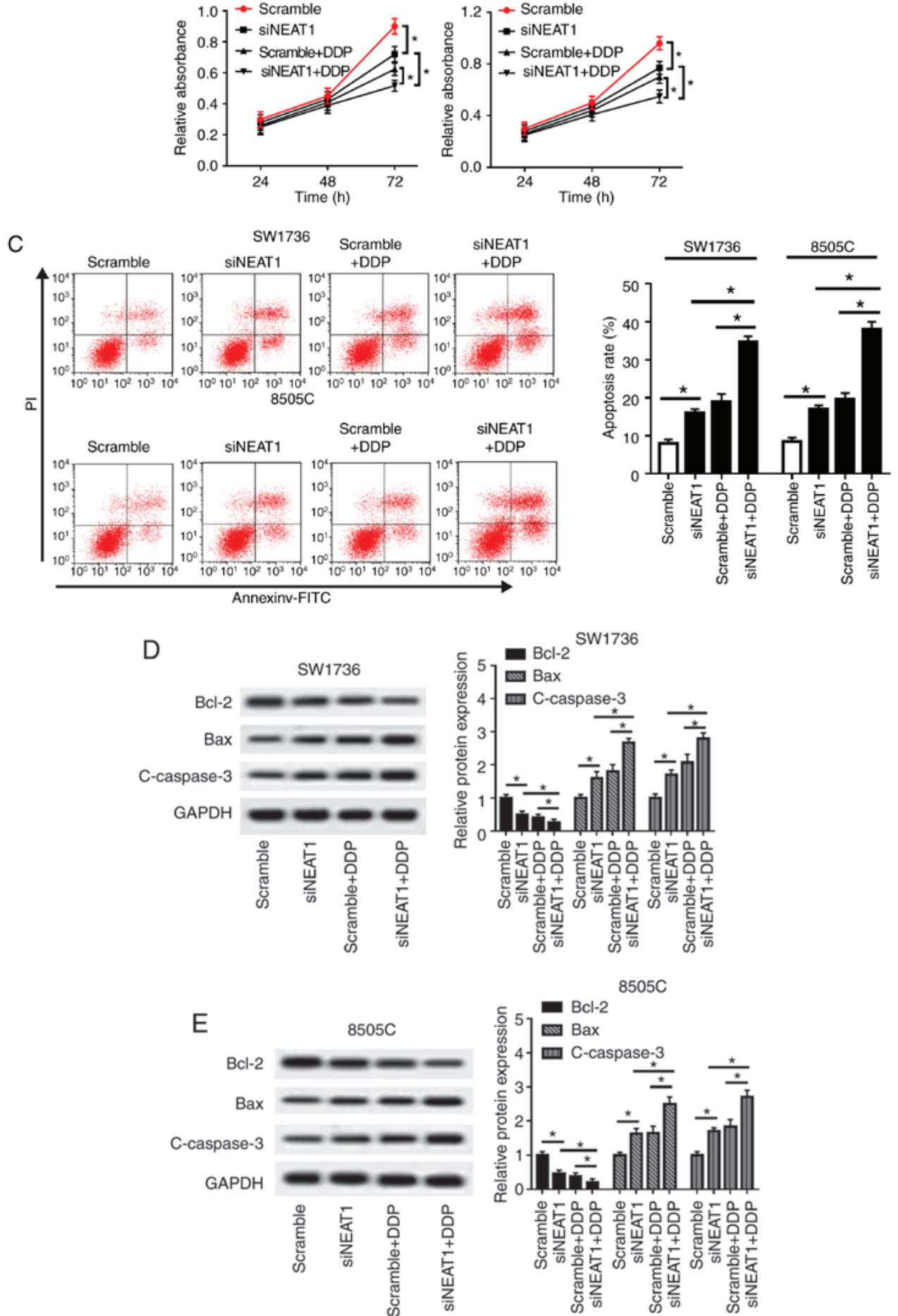

Figure 2. NEAT1 silencing decreases DDP-resistance of SW1736 and 8505C cells. SW1736 and 8505C cells were transfected with Scramble or siNEAT1, and were then stimulated with or without $30 \mu \mathrm{g} / \mathrm{ml}$ DDP. (A) NEAT1 expression was assessed by reverse transcription-quantitative PCR in transfected cells. (B) At the indicated times, cell proliferation was detected by Cell Counting kit- 8 in treated cells. (C) After $48 \mathrm{~h}$ of DDP treatment, cell apoptosis was measured by flow cytometry. (D and E) After $48 \mathrm{~h}$ of treatment, the expression levels of Bax, Bcl-2 and $\mathrm{C}$-caspase3 were determined by western blotting. ${ }^{*} \mathrm{P}<0.05$ as indicated. 

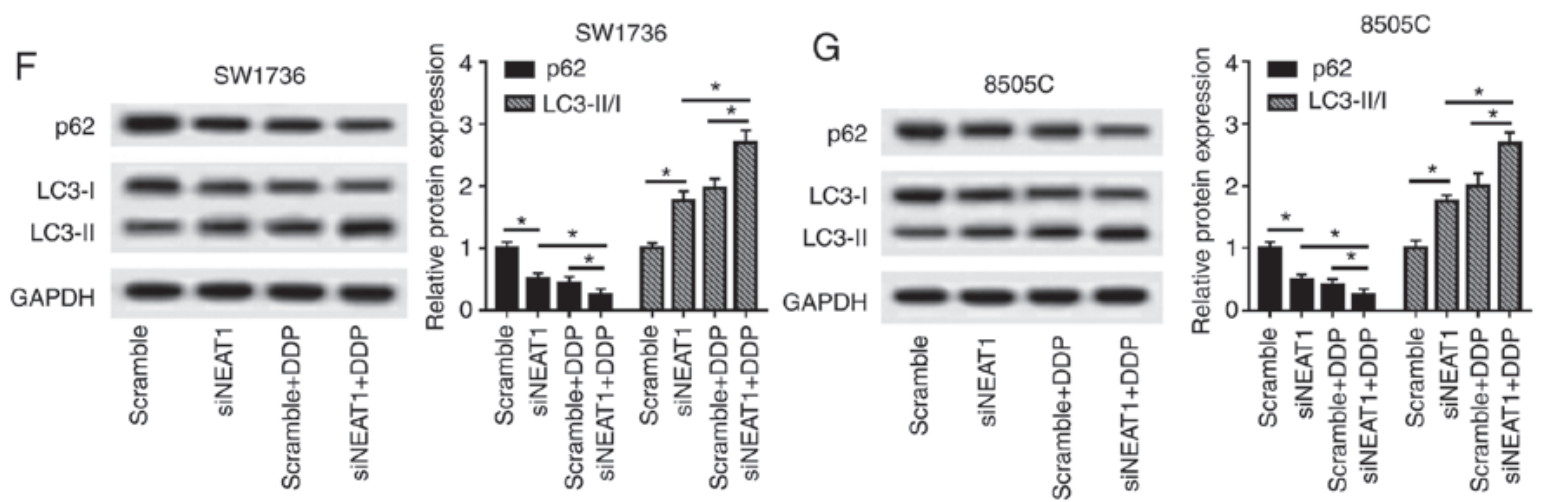

Figure 2. Continued. NEAT1 silencing decreases DDP-resistance of SW1736 and 8505C cells. (F and G) After $48 \mathrm{~h}$ of treatment, the expression levels of p62, LC3-I and LC3-II were assessed by western blotting in treated cells. "P<0.05 as indicated. C-, cleaved; DDP, cisplatin; LC3, microtubule-associated proteins 1A/1B light chain 3B; lncRNA, long non-coding RNA; NEAT1, nuclear paraspeckle assembly transcript 1; PI, propidium iodide; si, small interfering RNA.

\section{A \\ chr11:65192758-65192783[+] \\ miR-9-5p 3'-agtatGTCGA - - - TCTATTGGTTTCt-5' \\ NEAT1-wt 5'-gtcacCAGTTTTCCGAGAACCAAAGg-3' \\ NEAT1-mut $\quad$ 5'-gtcacGTCTATTCCCTGTTGGTTTCg-3'}
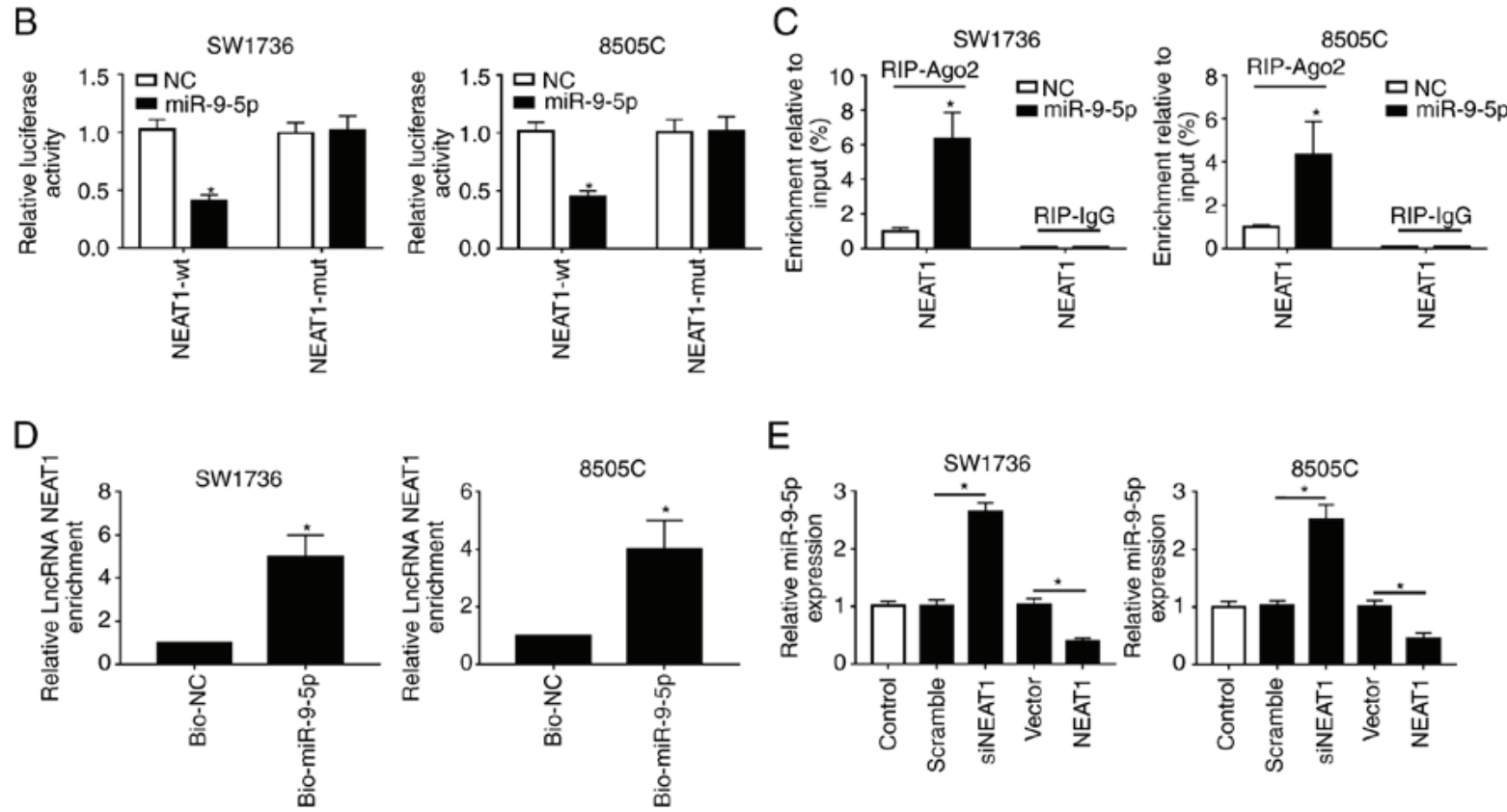

Figure 3. NEAT1 binds to miR-9-5p and suppresses it expression. (A) Schematic diagram of the predicted binding sites between NEAT1 and miR-9-5p, and the mutation in the binding sequence of NEAT1-mut. (B) Relative luciferase activities were assessed in SW1736 and 8505C cells cotransfected with NEAT1-wt or NEAT1-mut and miR-NC mimics or miR-9-5p mimics. (C) SW1736 and 8505C cells were transfected with miR-9-5p mimics or miR-NC mimics, and their lysates were incubated with anti-Ago2, followed by the measurement of NEAT1 enrichment by RT-qPCR assay. (D) SW1736 and $8505 \mathrm{C}$ cells were transfected with bio-miR-9-5p mimics or bio-NC mimics and their lysates were incubated with streptavidin-coupled beads to form bio-miRNA-lncRNA complexes, followed by the detection of NEAT1 enrichment. (E) RT-qPCR assay of miR-9-5p expression in SW1736 and 8505C cells transfected with Scramble, siNEAT1, Vector and Vector-NEAT1. "P<0.05 vs. NC, or as indicated. Ago2, Argonaute2; bio, biotinylated; lncRNA, long non-coding RNA; miR-9-5p, microRNA-9-5-p; mut, mutant; NC, negative control; NEAT1, nuclear paraspeckle assembly transcript 1; RIP, RNA immunoprecipiation; RT-qPCR, reverse transcription-quantitative PCR; si, small interfering RNA; wt, wild type.

miRNAs of NEAT1. Notably, the data revealed that miR-9-5p harbored putative binding sites with NEAT1 (Fig. 3A). To verify this finding, dual-luciferase reporter, RIP and RNA pull-down assays were performed. For the dual-luciferase reporter assay, NEAT1-wt or NEAT1-mut vectors were transfected into
SW1736 and 8505C cells, together with miR-9-5p or NC mimics. The results indicated that the luciferase activity of NEAT1-wt was markedly reduced post-transfection with miR-9-5p mimics; however, no change was observed in the activity of cells transfected with NEAT1-mut in the presence of miR-9-5p 
A

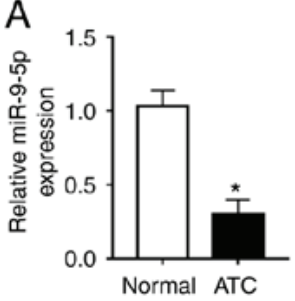

D

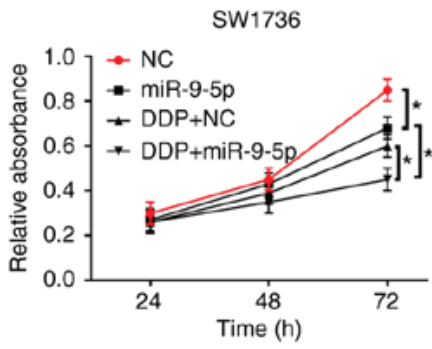

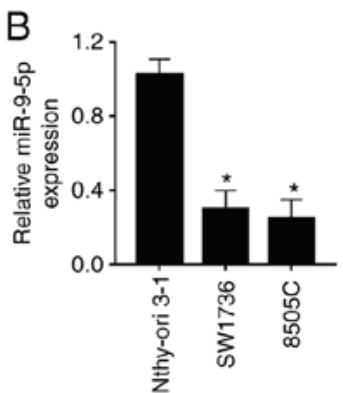

C

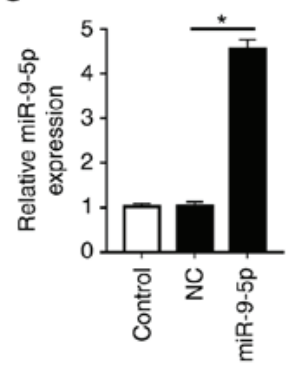

$8505 \mathrm{C}$

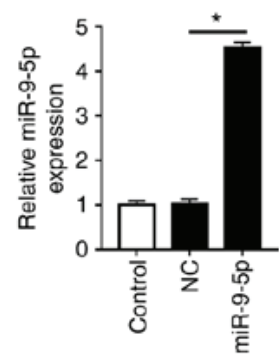

$8505 \mathrm{C}$

\section{E}

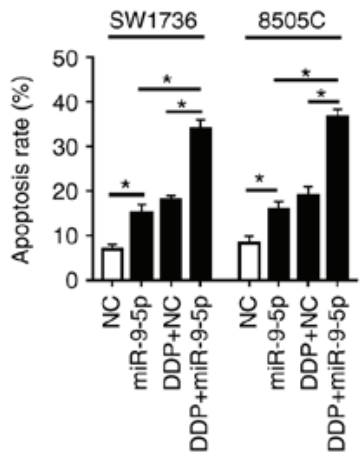

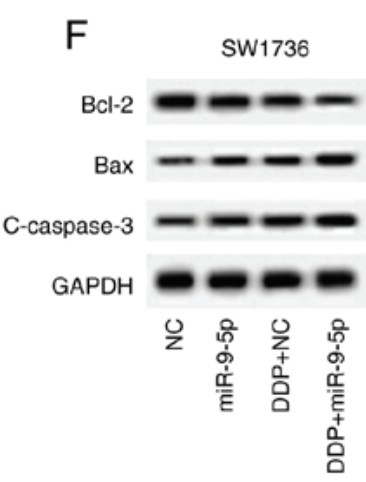

G

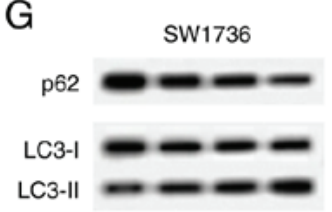

GAPDH

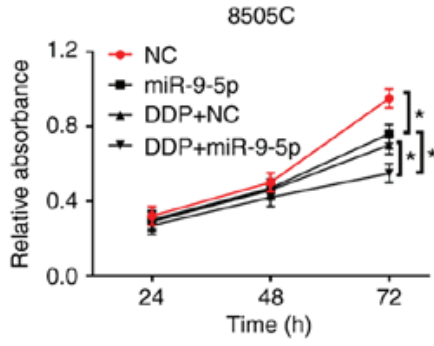

SW1736
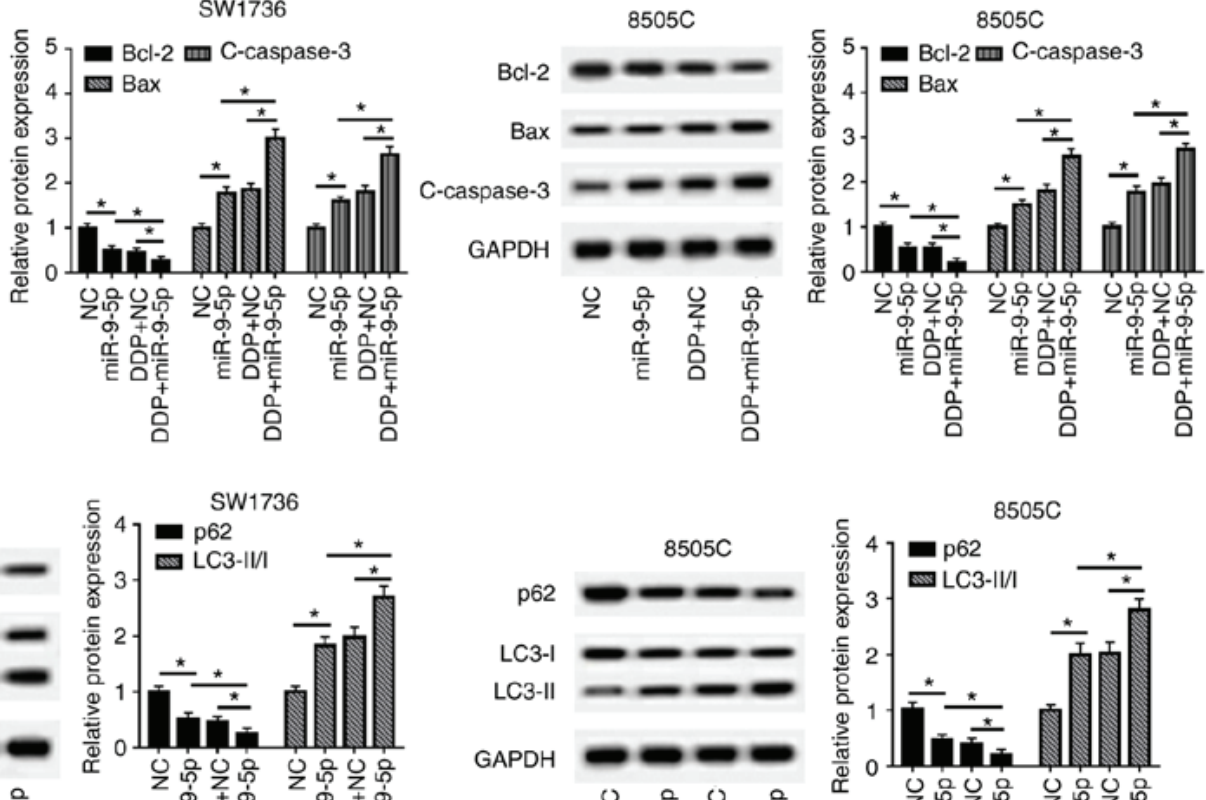

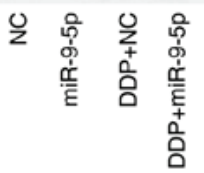

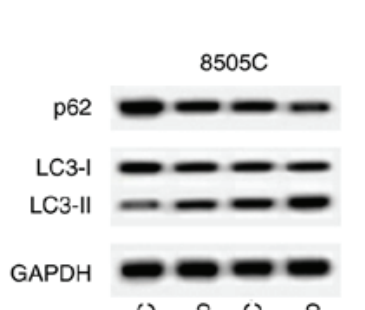

约

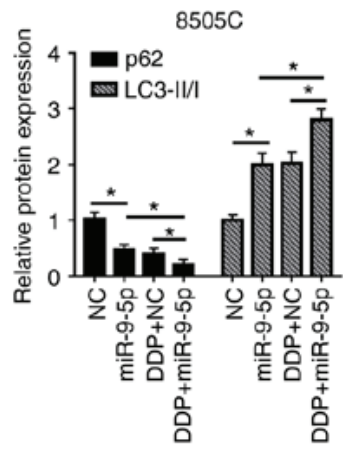

Figure 4. miR-9-5p sensitizes SW1736 and 8505C cells to DDP. RT-qPCR assay of miR-9-5p expression in (A) ATC tissues and adjacent normal thyroid tissues, and in (B) two ATC cell lines (SW1736 and 8505C) and Nthy-ori 3-1 cells. SW1736 and 8505C cells were transfected with miR-9-5p mimics or miR-NC mimics, and were then treated with or without DDP, followed by (C) determination of miR-9-5p expression by RT-qPCR assay, (D) cell proliferation by Cell Counting kit-8 assay, (E) cell apoptosis by flow cytometry, and the expression levels of (F) Bax, Bcl-2 and C-caspase3, and (G) p62, LC3-I, LC3-II and GAPDH by western blotting. "P<0.05, as indicated. ATC, anaplastic thyroid carcinoma; C-, cleaved; DDP, cisplatin; LC3, microtubule-associated proteins $1 \mathrm{~A} / 1 \mathrm{~B}$ light chain 3B; miR-9-5p, microRNA-9-5-p; NC, negative control; RT-qPCR, reverse transcription-quantitative PCR.

mimics (Fig. 3B). For the RIP assay, cells were transfected with miR-9-5p mimics, and lysates were incubated with anti-Ago2. As presented in Fig. 3C, NEAT1 was substantially enriched in the presence of miR-9-5p mimics. Additionally, for the RNA pull-down assay, cells were transfected with bio-miR-9-5p and lysates were incubated with streptavidin-coupled beads to form bio-miRNA-lncRNA complexes. As shown in Fig. 3D, NEAT1 enrichment was higher in the bio-miR-9-5p group compared with in the control group. Furthermore, this study aimed to determine whether NEAT1 regulated miR-9-5p expression in SW1736 and 8505C cells by transfecting cells with siNEAT1 or Vector-NEAT1. RT-qPCR assays demonstrated that miR-9-5p expression was significantly elevated by NEAT1 silencing, whereas it was reduced in the presence of Vector-NEAT1 (Fig. 3E). These results indicated that NEAT1 may directly target miR-9-5p. 
A

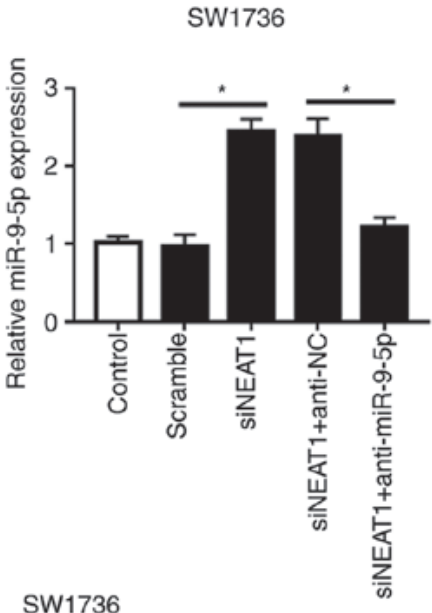

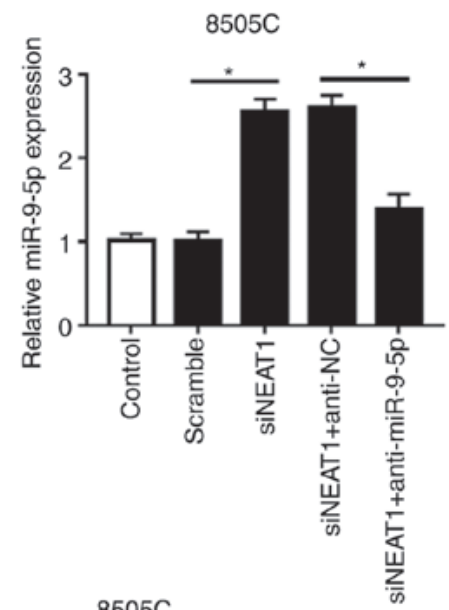
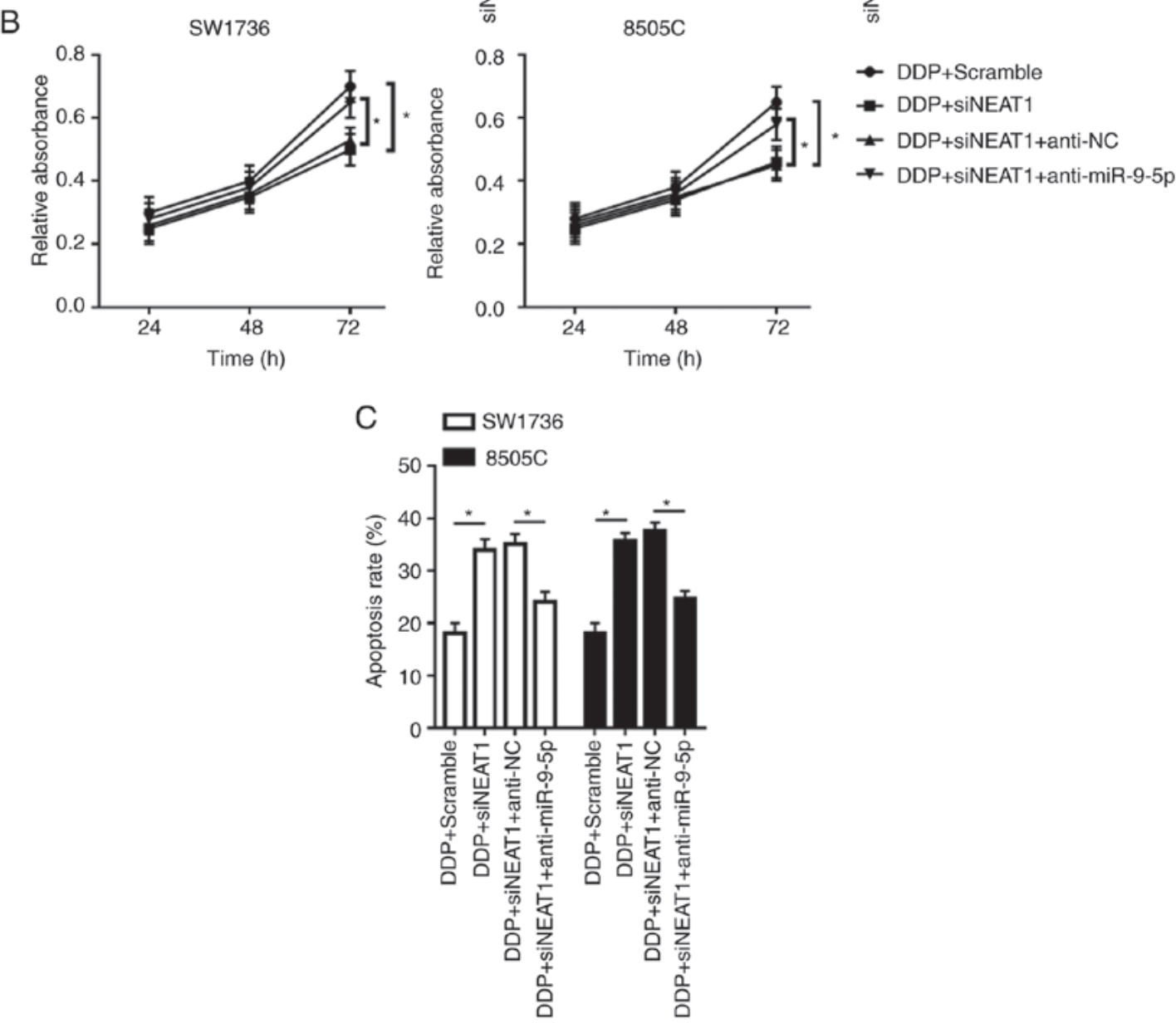

Figure 5. Inhibitory role of NEAT1 silencing on DDP-resistance of SW1736 and 8505C cells is mediated by miR-9-5p. SW1736 and 8505C cells were transfected with Scramble, siNEAT1, siNEAT1 + anti-NC or siNEAT1 + anti-miR-9-5p, and were then treated with or without DDP, followed by measurement of (A) miR-9-5p expression by reverse transcription-quantitative PCR assay, (B) cell proliferation by Cell Counting kit-8 assay, (C) cell apoptosis by flow cytometry. ${ }^{*} \mathrm{P}<0.05$, as indicated.

miR-9-5p sensitizes SW1736 and $8505 C$ cells to DDP. The present study detected miR-9-5p expression in ATC tissues and cell lines. The results revealed that miR-9-5p was significantly downregulated in ATC tissues and cell lines compared with in controls (Fig. 4A and B). Subsequently, in order to explore the effects of miR-9-5p on DDP-resistance in ATC, gain-of-function experiments were performed by transfecting SW1736 and 8505C cells with miR-9-5p mimics, followed by treatment with or without DDP. As presented in Fig. 4C, transfection with miR-9-5p mimics resulted in a $\sim 4.55$-fold increase of miR-9-5p expression in SW1736 cells, and a 4.53 -fold increase in $8505 \mathrm{C}$ cells. Furthermore, functional experiments demonstrated that miR-9-5p overexpression in SW1736 and 8505C cells led to a decrease in cell proliferation (Fig. 4D), an enhancement of cell apoptosis (Fig. 4E and F), and promotion of cell autophagy (Fig. 4G). Furthermore, simultaneous miR-9-5p overexpression and DDP treatment led to a more distinct inhibition on cell proliferation, and a more obvious promotion on cell apoptosis and autophagy compared with 
D
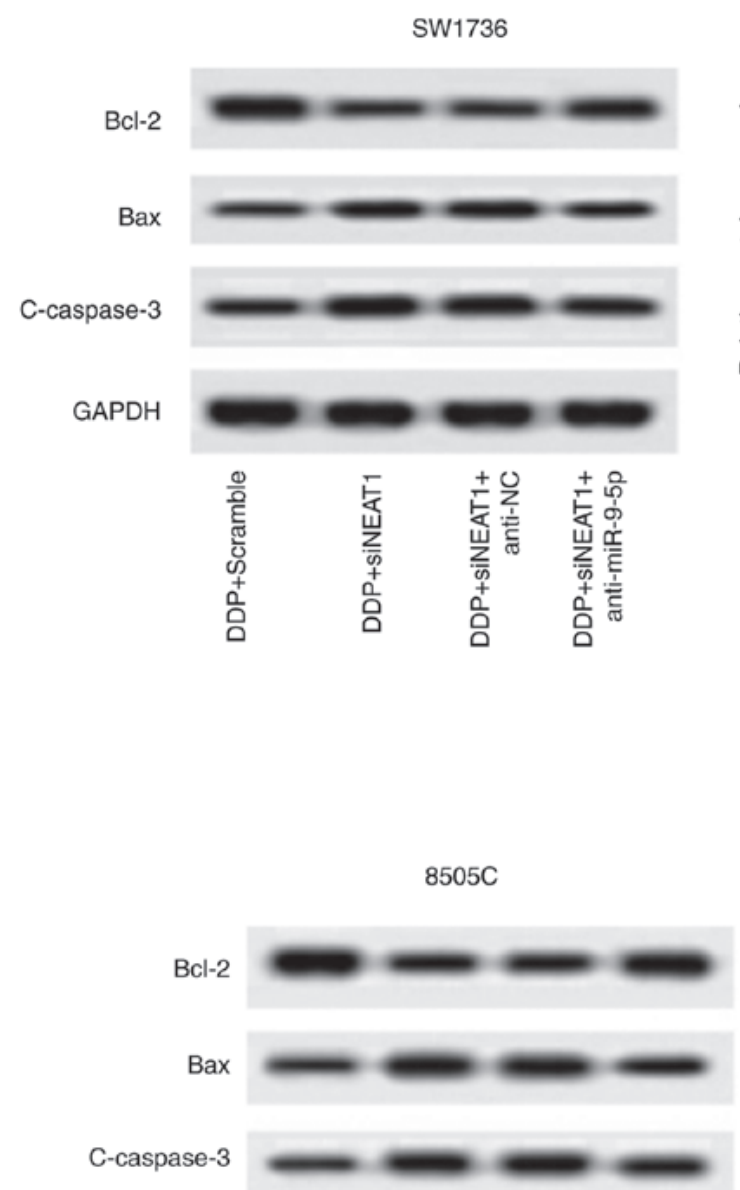

GAPDH

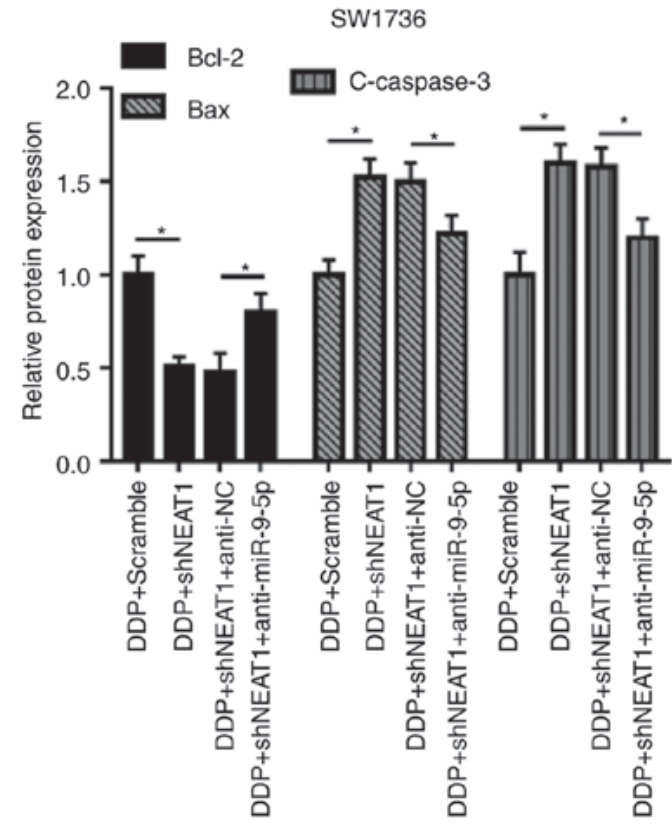

$8505 C$

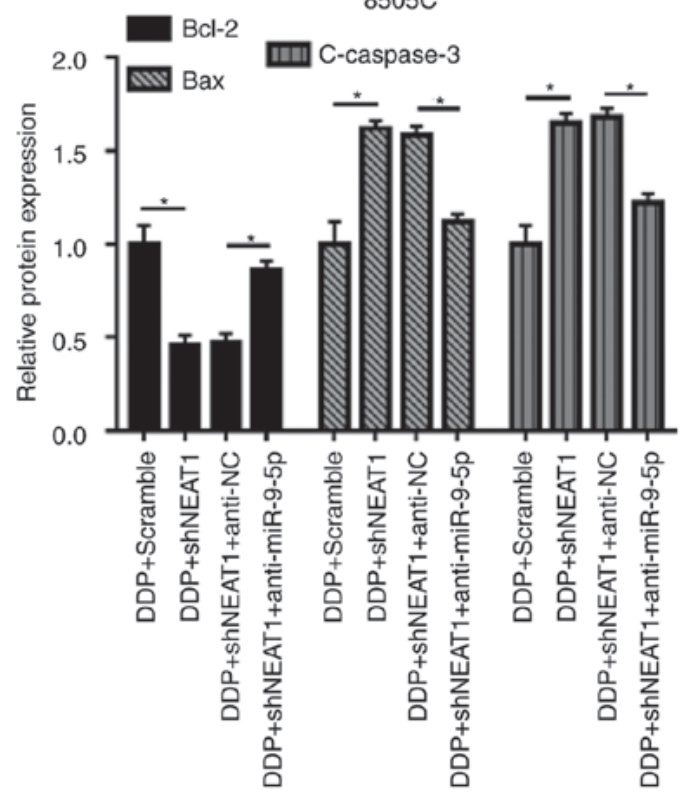

Figure 5. Continued. Inhibitory role of NEAT1 silencing on DDP-resistance of SW1736 and 8505C cells is mediated by miR-9-5p. SW1736 and 8505C cells were transfected with Scramble, siNEAT1, siNEAT1 + anti-NC or siNEAT1 + anti-miR-9-5p, and were then treated with or without DDP, followed by measurement of the expression levels (D) Bax, Bcl-2 and C-caspase 3 by western blotting. ${ }^{*} \mathrm{P}<0.05$, as indicated.

miR-9-5p mimics alone or NC + DDP group (Fig. 4D-G). Taken together, these results indicated that miR-9-5p may sensitize SW1736 and 8505C cells to DDP.

Inhibitory role of NEAT1 silencing on DDP-resistance of SW1736 and $8505 \mathrm{C}$ cells is mediated by miR-9-5p. To provide further mechanistic insight into the association between NEAT1 and miR-9-5p on DDP-resistance in ATC, SW1736 and $8505 \mathrm{C}$ cells were cotransfected with siNEAT1 and anti-miR-9-5p, followed by treatment with or without DDP. As shown in Fig. 5A, cotransfection with anti-miR-9-5p markedly antagonized the enhancing effects of NEAT1 silencing on miR-9-5p expression. CCK-8 assay revealed that compared with NC cotransfection, anti-miR-9-5p cotransfection in
SW1736 and 8505C cells antagonized the inhibitory effects of NEAT1 silencing on cell proliferation upon DDP treatment (Fig. 5B). Further functional experiments demonstrated that the effects of NEAT1 silencing on cell apoptosis and autophagy were markedly reduced following cotransfection with anti-miR-9-5p (Fig. 5C-E).

SPAG9 is a direct target of miR-9-5p. TargetScan Human software was used to predict the target genes of miR-9-5p. The results revealed that the 3'-UTR of SPAG9 mRNA contained a putative complementary site of miR-9-5p (Fig. 6A). To confirm whether SPAG9 was a target of miR-9-5p, dual-luciferase reporter and RIP assays were performed. Compared with in the NC group, the luciferase activities of SPAG9-wt in 
E
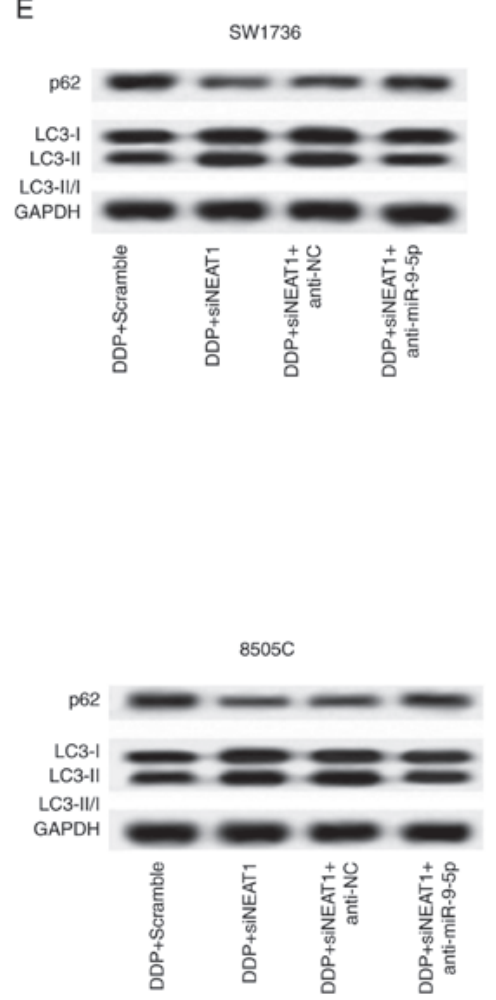

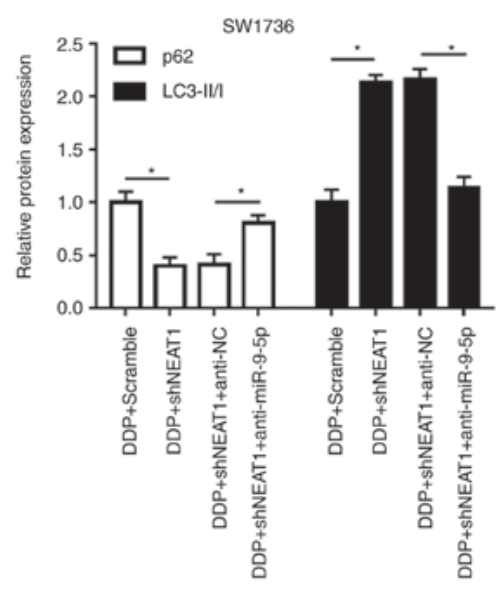

$8505 \mathrm{C}$

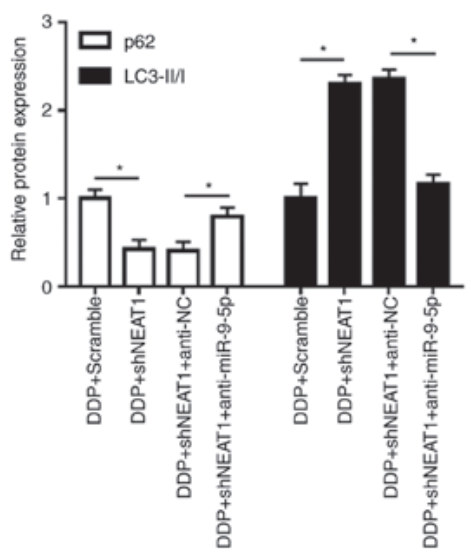

Figure 5. Continued. Inhibitory role of NEAT1 silencing on DDP-resistance of SW1736 and 8505C cells is mediated by miR-9-5p. SW1736 and $8505 \mathrm{C}$ cells were transfected with Scramble, siNEAT1, siNEAT1 + anti-NC or siNEAT1 + anti-miR-9-5p, and were then treated with or without DDP, followed by measurement of the expression levels (E) p62, LC3-I and LC3-II by western blotting. " $\mathrm{P}<0.05$, as indicated. C-, cleaved; DDP, cisplatin; LC3, microtubule-associated proteins 1A/1B light chain 3B; miR-9-5p, microRNA-9-5-p; NC, negative control; NEAT1, nuclear paraspeckle assembly transcript 1; si, small interfering RNA.
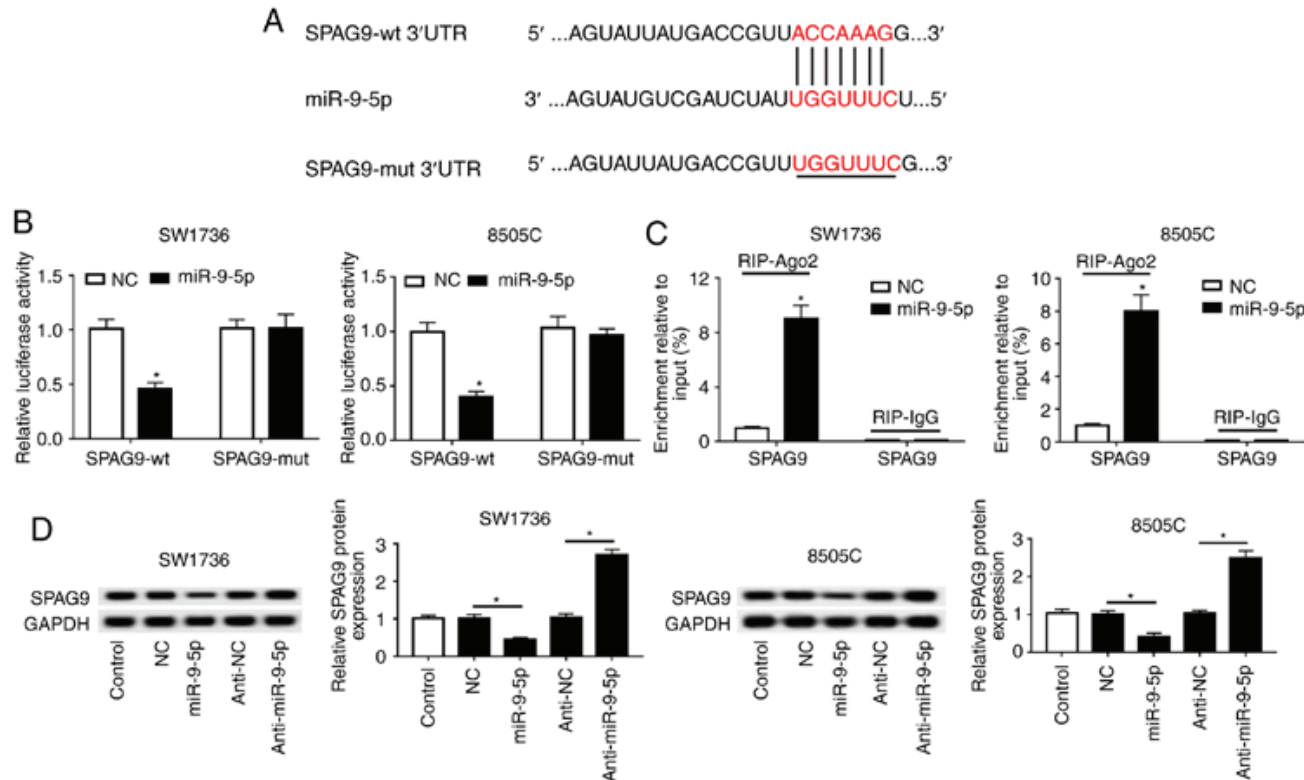

Figure 6. SPAG9 is a direct target gene of miR-9-5p. (A) Schematic diagram of the predicted binding sites between miR-9-5p and SPAG9, and the mutation in seeded region of SPAG9-mut. (B) Relative luciferase activities were detected in SW1736 and 8505C cells cotransfected with SPAG9-wt or SPAG-mut and miR-NC mimics or miR-9-5p mimics. (C) SW1736 and 8505C cells were transfected with miR-NC mimics or miR-9-5p mimics, and their lysates were incubated with anti-Ago2 or anti-IgG, followed by the measurement of SPAG9 mRNA enrichment by reverse transcription-quantitative PCR assay. (D) Western blot analysis of SPAG9 expression in SW1736 and 8505C cells transfected with miR-NC mimics, miR-9-5p mimics, anti-miR-NC or anti-miR-9-5p. "P<0.05 vs. NC, or as indicated. 3'-UTR, 3'-untranslated region; Ago2, Argonaute2; miR-9-5p, microRNA-9-5-p; mut, mutant; NC, negative control; SPAG9, sperm-associated antigen 9; wt, wild type. 

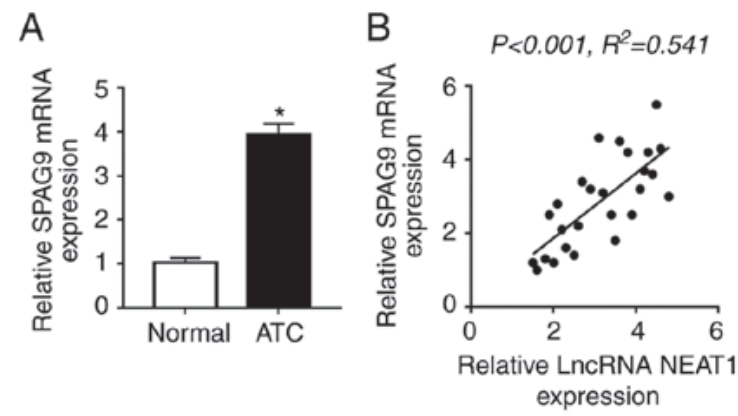

$\mathrm{E}$
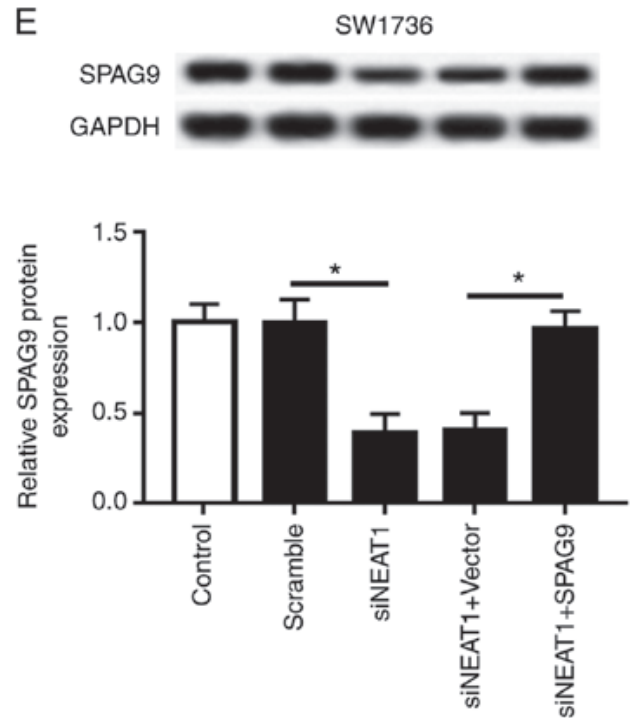

$\mathrm{F}$

SW1736

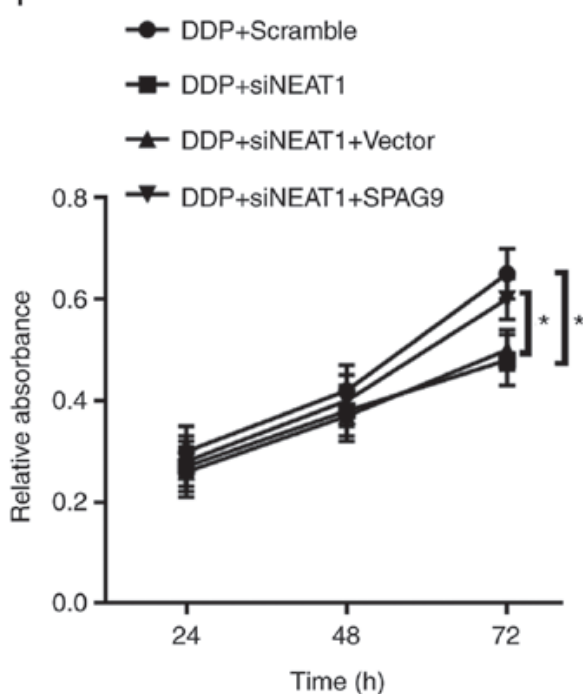

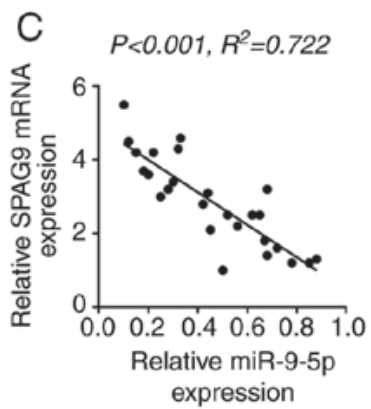

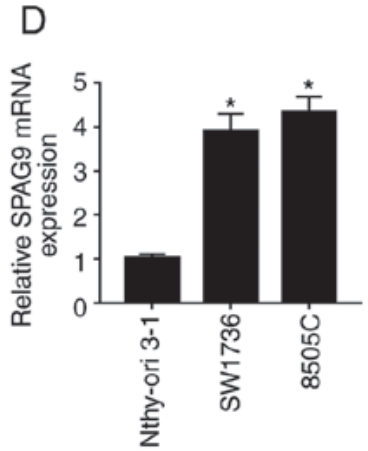

$8505 \mathrm{C}$

\section{SPAG9}

GAPDH
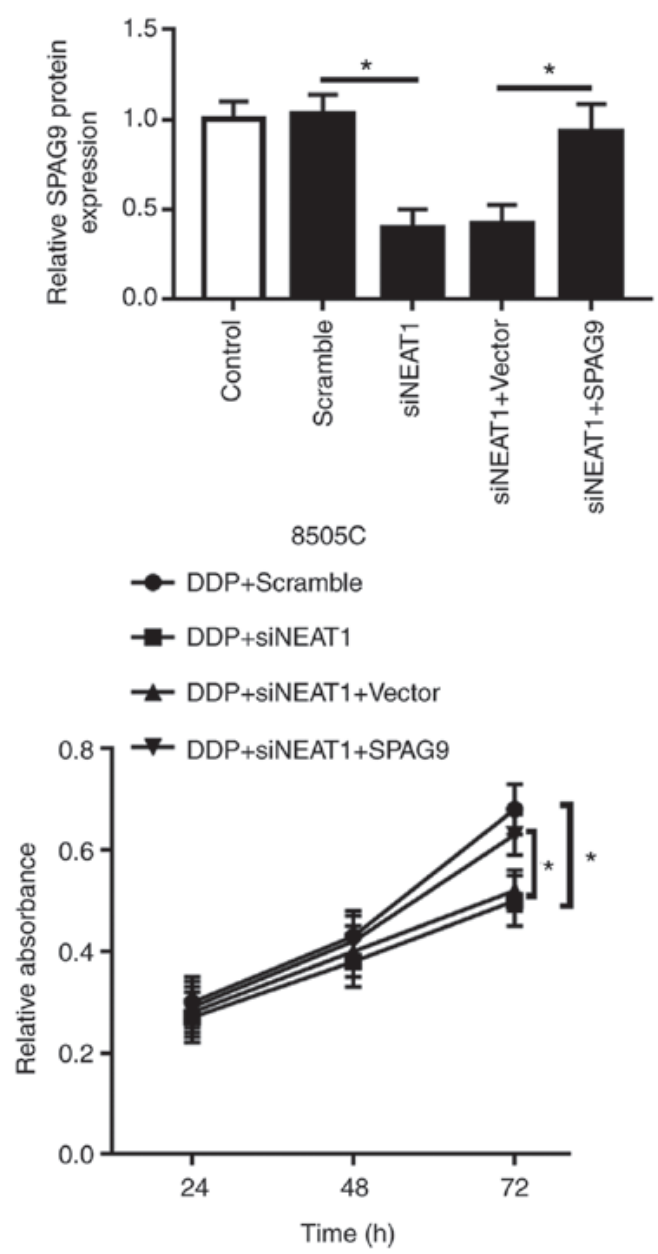

Figure 7. Inhibitory role of NEAT1 silencing on DDP-resistance is antagonized by SPAG9 in SW1736 and 8505C cells. (A) RT-qPCR assay of SPAG9 mRNA expression in ATC tissues and adjacent normal thyroid tissues. Correlation between (B) SPAG9 mRNA and NEAT1 expression or (C) SPAG9 mRNA and miR-9-5p expression was determined. (D) RT-qPCR assay of SPAG9 mRNA expression in two ATC cell lines (SW1736 and 8505C) and Nthy-ori 3-1 cells. SW1736 and 8505C cells were transfected with Scramble, siNEAT1, siNEAT1 + Vector or siNEAT1 + Vector-SPAG9, followed by detection of (E) SPAG9 expression by western blotting. SW1736 and 8505C cells were transfected with Scramble, siNEAT1, siNEAT1 + Vector or siNEAT1 + Vector-SPAG9, and were then treated with DDP, followed by the measurement of (F) cell proliferation by Cell Counting kit- 8 assay. "P<0.05 vs. as indicated.

SW1736 and 8505C cells were significantly weakened by miR-9-5p overexpression (Fig. 6B). Conversely, there was little change in the luciferase activities of SPAG9-mut in the presence of miR-9-5p mimics (Fig. 6B). Furthermore, miR-9-5p overexpression resulted in an abundant enrichment of SPAG9
mRNA with anti-Ago2 in SW1736 and 8505C cells (Fig. 6C). In addition, this study verified whether miR-9-5p affected the expression of SPAG9. Western blot analysis demonstrated that miR-9-5p negatively regulated SPAG9 expression in SW1736 and $8505 \mathrm{C}$ cells (Fig. 6D). 

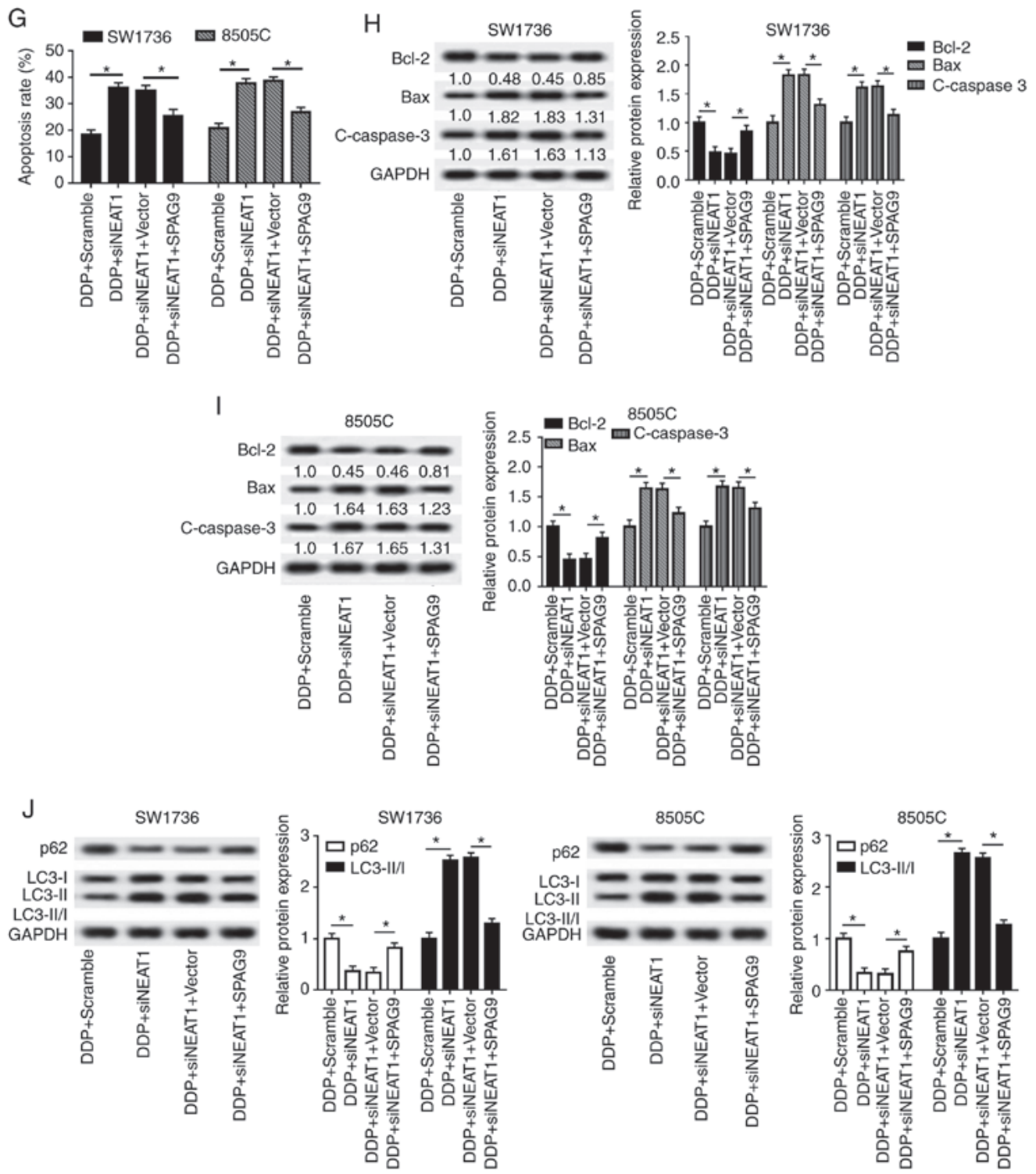

Figure 7. Continued. Inhibitory role of NEAT1 silencing on DDP-resistance is antagonized by SPAG9 in SW1736 and 8505C cells. SW1736 and $8505 \mathrm{C}$ cells were transfected with Scramble, siNEAT1, siNEAT1 + Vector or siNEAT1 + Vector-SPAG9, and were then treated with DDP, followed by the measurement of (G) cell apoptosis by flow cytometry, and the expression levels of (H and I) Bax, Bcl-2 and C-caspase3, and (J) p62, LC3-I and LC3-II by western blotting. ${ }^{\text {"P }}<0.05$ vs. as indicated. C-, cleaved; DDP, cisplatin; LC3, microtubule-associated proteins 1A/1B light chain 3B; NC, negative control; NEAT1, nuclear paraspeckle assembly transcript 1; RT-qPCR, reverse transcription-quantitative PCR; si, small interfering RNA.

SPAG9 antagonizes the inhibitory role of NEAT1 silencing on DDP-resistance of SW1736 and 8505 C cells. As expected, SPAG9 mRNA expression was highly upregulated in ATC tissues compared with in normal control tissues (Fig. 7A). Furthermore, SPAG9 mRNA expression was positively correlated with NEAT1 expression, whereas it was inversely correlated with miR-9-5p expression in ATC tissues (Fig. 7B and C). In addition, SPAG9 mRNA expression was also increased in ATC cell lines (Fig. 7D).

The present study aimed to determine whether SPAG9 was involved in the regulatory effect of NEAT1 on DDP-resistance in ATC. The results showed that NEAT1 silencing resulted in a significant decrease in SPAG9 expression in SW1736 and $8505 \mathrm{C}$ cells, whereas this effect was abrogated by cotransfection with Vector-SPAG9 (Fig. 7E). Further functional experiments demonstrated that the regulatory effect of NEAT1 silencing on cell proliferation, apoptosis and autophagy upon
DDP treatment were markedly reversed by SPAG9 expression restoration in SW1736 and 8505C cells (Fig. 7F-J).

NEAT1 silencing decreases DDP-resistance in tumors in vivo. Given the present in vitro findings, this study further evaluated the role of NEAT1 in DDP-resistance of tumors in vivo. SW1736 and 8505C cells infected with lenti-Scramble or lenti-shNEAT1 were subcutaneously injected into nude mice to develop xenografts, followed by treatment with DDP or PBS. At the end of the in vivo experiments, the average diameter of the control tumors reached approximately $10 \mathrm{~mm}$ (Fig. 8A and B). The present results revealed that shNEAT1 transfection or DDP treatment highly suppressed tumor growth compared with in the respective control groups; this was presented as a decrease in tumor volume and weight (Fig. 8A and B). Furthermore, simultaneous shNEAT1 transfection and DDP treatment resulted in a more distinct 

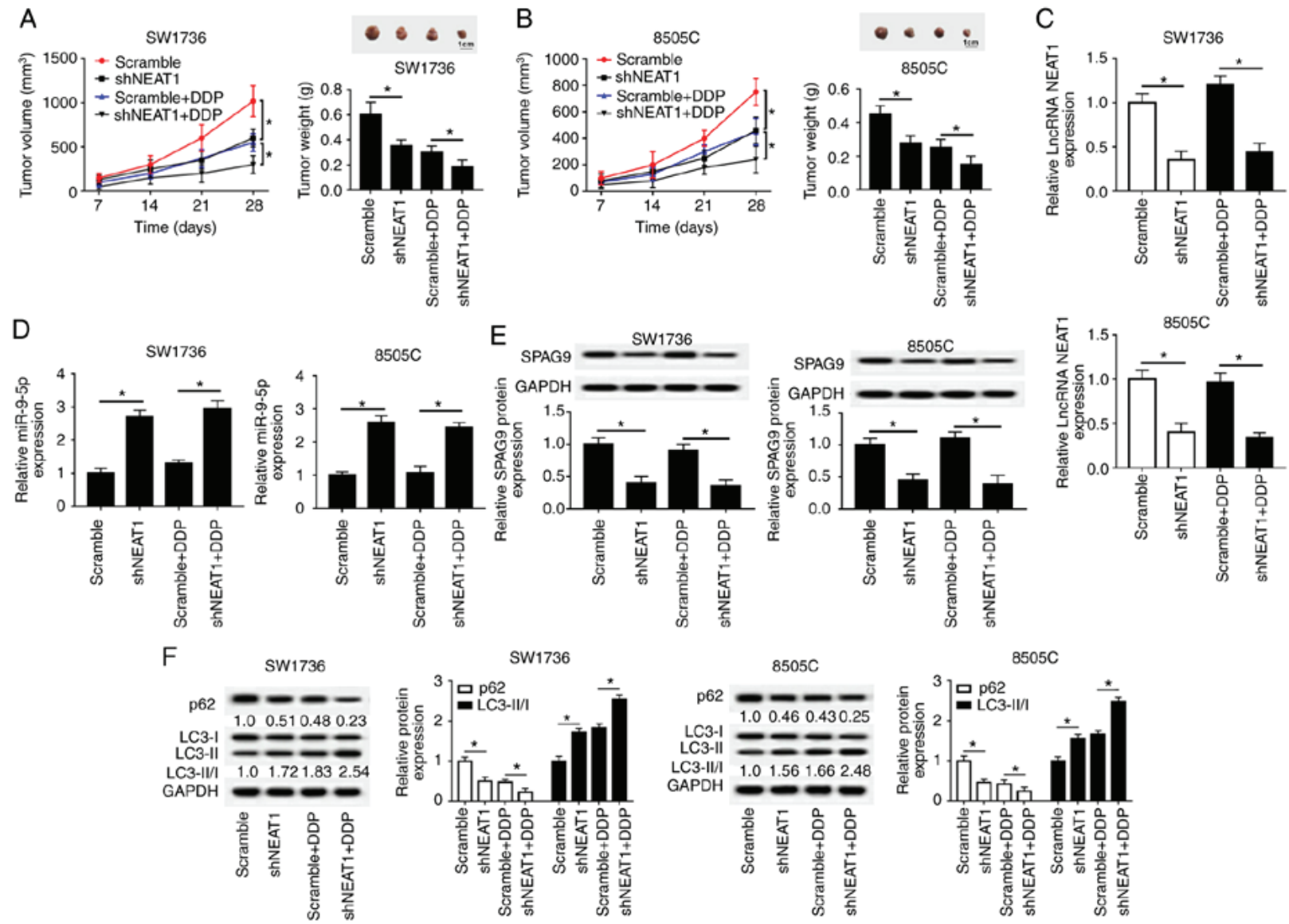

Figure 8. NEAT1 silencing decreases DDP-resistance of tumors in vivo. Briefly, 5.0x10 $\mathrm{SW} 1736$ and 8505C cells stably transfected with lenti-Scramble or lenti-shNEAT1 were subcutaneously injected into nude mice to develop xenografts $(\mathrm{n}=8)$. At 3 days after injection, PBS solution or DDP solution $(3 \mathrm{mg} / \mathrm{kg})$ were intravenously administered into each mouse every 4 days. After 4 weeks, mice were sacrificed. (A and B) Tumor volume, tumor images and average weight were analyzed in excised tumor tissues. (C and D) Reverse transcription-quantitative PCR assay of NEAT1 and miR-9-5p expression in xenograft tissues. (E and F) Western blot analysis of SPAG9, p62, LC3-I and LC3-II levels in xenograft tumor tissues. "P<0.05 vs. as indicated. DDP, cisplatin; LC3, microtubule-associated proteins 1A/1B light chain 3B; lncRNA, long non-coding RNA; NEAT1, nuclear paraspeckle assembly transcript 1; sh, short hairpin RNA.

inhibition on tumor growth, suggesting the inhibitory role of NEAT1 silencing on the DDP-resistance of ATC cells in vivo (Fig. 8A and B). In addition, NEAT1 and SPAG9 expression levels were downregulated, whereas miR-9-5p expression was upregulated in tumors derived from lenti-shNEAT1-infected cells with or without DDP treatment (Fig. 8C-E). Additionally, western blot analysis indicated that NEAT1 silencing led to a decrease in p62 expression and an increase in LC3-II/I expression in xenograft tissues with or without DDP treatment (Fig. 8F).

\section{Discussion}

Accumulating evidence has suggested that lncRNAs are tightly linked to cancer chemoresistance, providing a possibility that lncRNAs may be potential therapeutic targets for chemoresistant cancer. For example, Han et al (20) reported that the IncRNA colorectal neoplasia differentially expressed contributes to 5-fluoruracil-resistance in colorectal cancer cell through sponging miR-181a-5p and regulating Wnt/ $\beta$-catenin signaling. Gu et al (21) demonstrated that HOXD antisense growth-associated lncRNA knockdown ameliorates the chemoresistance of castration-resistant prostate cancer cells by recruiting WD repeat domain 5. Additionally,
Yoshida et al (22) reported that curcumin sensitizes pancreatic cancer cells to gemcitabine through weakening lncRNA PVT1 expression. Furthermore, Wang et al (23) verified that the IncRNA papillary thyroid carcinoma susceptibility candidate 3 ameliorates drug resistance of ATC cells to doxorubicin by regulating the STAT3/INO80 pathway.

The present study demonstrated that NEAT1 was upregulated in ATC tissues and cell lines, and NEAT1 silencing sensitized ATC cell lines to DDP. Similar to these findings, inhibition of NEAT1 has been reported to attenuate chemoresistance in a series of cancer cells, including nasopharyngeal carcinoma cells (24), gastric cancer cells (25) and lung cancer cells (26). Furthermore, Adriaens et al (27) demonstrated that NEAT1 knockdown sensitizes MCF-7 cells to DNA-damaging agents, such as doxorubicin or platinum compounds. Parasramka et al (28) also verified that NEAT1 depletion leads to a reduction in tumor cell proliferation under gemcitabine treatment, indicating it as a downstream effector of gemcitabine sensitivity in cholangiocarcinoma.

It is widely accepted that lncRNAs may act as 'miRNA sponges' to protect target mRNAs from suppression by sequestering target miRNAs (15). Therefore, StarBase v.2.0 software was used to search for the target miRNAs of NEAT1. Among 
these candidates, miR-9-5p was selected for further analysis, due to its crucial involvement in human cancer (29-33). In addition, this study verified that NEAT1 suppressed miR-9-5p expression by directly binding to miR-9-5p; this finding is consistent with a recent study (29). miR-9-5p results from the transcription of miR-9 genes located on chromosomes 1,5 and 15 , and functions as an oncogene or a tumor suppressor involved in the carcinogenesis and metastatic process of numerous types of cancer (30), such as breast cancer (31), colorectal cancer (32) and glioblastoma (33). Furthermore, miR-9 overexpression is associated with decreased resistance of primary epithelial ovarian cancer cells to DDP treatment (34). miR-9 also promotes DDP-sensitivity of non-small lung cancer cells by targeting eukaryotic translation inhibition factor 5A2 (35). Conversely, miR-9 has been reported to enhance the resistance of glioblastoma multiforme cells to temozolomide via a Sonic Hedgehog-independent method by targeting patched 1 (36). In this study, it was reported that miR-9-5p was downregulated in ATC tissues and cell lines, suggesting its role as a potential tumor suppressor in ATC, in accordance with a recent study (37). Furthermore, the present data indicated that miR-9-5p sensitized ATC cell lines to DDP, which is similar to the findings of previous studies by Zhao et al and Pan et al $(34,35)$. Furthermore, this study validated that the inhibitory role of NEAT1 silencing on DDP-resistance of ATC cell lines was mediated by miR-9-5p.

TargetScan software was used to predict the target genes of miR-9-5p. Among these candidates, SPAG9 was selected for further study due to its well-recognized oncogenic role in human cancer, including in endometrial carcinoma (38), lung cancer (39) and triple-negative breast cancer (40). Additionally, SPAG9 expression is upregulated in the peripheral blood of patients with hepatocellular carcinoma and lung cancer, highlighting its role as a potential tumor-specific biomarker for tumor detection, therapy and prognosis (41). SPAG9 has also been demonstrated to be involved in the progression of thyroid cancer (42). Furthermore, SPAG9 overexpression enhances drug resistance of breast cancer cells to taxol (43). This study validated that SPAG9 was a direct target of miR-9-5p, and confirmed that SPAG9 mRNA expression levels were upregulated in ATC tissues and cell lines. Furthermore, SPAG9 expression was positively correlated with NEAT1 expression, whereas it was inversely correlated with miR-9-5p expression in ATC tissues. The inhibitory role of NEAT1 silencing on DDP-resistance of ATC cell lines was antagonized by SPAG9.

Finally, the present study demonstrated that NEAT1 silencing might decrease DDP-resistance of tumors in vivo partly by regulating the miR-9-5p/SPAG9 axis. Since the number of mice was relatively small and no ATC mouse model was generated, the role and molecular mechanism of NEAT1 on DDP-resistance of ATC in vivo cannot be confirmed. Therefore, further studies regarding the relationship between NEAT1 and DDP-resistance of ATC in vivo are required.

In conclusion, this study revealed that NEAT1 silencing ameliorated DDP-resistance of ATC cells, at least in part by reducing miR-9-5p sponging and regulating SPAG9 expression. Targeting NEAT1 may be a potential therapeutic strategy for the treatment of DDP-resistant ATC.

\section{Acknowledgements}

Not applicable.

\section{Funding}

The present study was supported by Henan Provincial People's Hospital.

\section{Availability of data and materials}

The datasets used and/or analyzed during the current study are available from the corresponding author on reasonable request.

\section{Authors' contributions}

This study was designed and conceived by PY and ZS. The experimental procedures and data analysis were carried out by PY,ZS, $\mathrm{ZZ}$ and TG. The manuscript was prepared by PY and ZZ. All authors read and approved the final manuscript.

\section{Ethics approval and consent to participate}

The study was approved by the Institutional Ethics Review Board of Henan Provincial People's Hospital; all patients provided prior written informed consent. All animal experiments were carried out following the national standard of the care and use of laboratory animals, and the study was approved by the Committee of Animal Research of Henan Provincial People's Hospital.

\section{Patient consent for publication}

Not applicable.

\section{Competing interests}

The authors declare that they have no competing interests.

\section{References}

1. Molinaro E, Romei C, Biagini A, Sabini E, Agate L, Mazzeo S, Materazzi G, Sellari-Franceschini S, Ribechini A, Torregrossa L, et al: Anaplastic thyroid carcinoma: From clinicopathology to genetics and advanced therapies. Nat Rev Endocrinol 13: 644-660, 2017.

2. Smallridge RC and Copland JA: Anaplastic thyroid carcinoma: Pathogenesis and emerging therapies. Clin Oncol (R Coll Radiol) 22: 486-497, 2010.

3. Quinn JJ and Chang HY: Unique features of long non-coding RNA biogenesis and function. Nat Rev Genet 17: 47-62, 2016.

4. Murugan AK, Munirajan AK and Alzahrani AS: Long noncoding RNAs: Emerging players in thyroid cancer pathogenesis. Endocr Relat Cancer 25: R59-R82, 2018.

5. Chakravarty D, Sboner A, Nair SS, Giannopoulou E, Li R, Hennig S, Mosquera JM, Pauwels J, Park K, Kossai M, et al: The oestrogen receptor alpha-regulated lncRNA NEAT1 is a critical modulator of prostate cancer. Nat Commun 5: 5383, 2014.

6. Chen ZJ, Zhang Z, Xie BB and Zhang HY: Clinical significance of up-regulated lncRNA NEAT1 in prognosis of ovarian cancer. Eur Rev Med Pharmacol Sci 20: 3373-3377, 2016.

7. Choudhry H, Albukhari A, Morotti M, Haider S, Moralli D, Smythies J, Schödel J, Green CM, Camps C, Buffa F, et al: Tumor hypoxia induces nuclear paraspeckle formation through HIF-2a dependent transcriptional activation of NEAT1 leading to cancer cell survival. Oncogene 34: 4482-4490, 2015. 
8. Chen X, Kong J, Ma Z, Gao S and Feng X: Up regulation of the long non-coding RNA NEAT1 promotes esophageal squamous cell carcinoma cell progression and correlates with poor prognosis. Am J Cancer Res 5: 2808-2815, 2015.

9. Hu Y, Yang Q, Wang L, Wang S, Sun F, Xu D and Jiang J: Knockdown of the oncogene lncRNA NEAT1 restores the availability of miR-34c and improves the sensitivity to cisplatin in osteosarcoma. Biosci Rep 38: pii: BSR20180375, 2018.

10. An J, Lv W and Zhang Y: LncRNA NEAT1 contributes to paclitaxel resistance of ovarian cancer cells by regulating ZEB1 expression via miR-194. Onco Targets Ther 10: 5377-5390, 2017.

11. Gao C, Zhang J, Wang Q and Ren C: Overexpression of IncRNA NEAT1 mitigates multidrug resistance by inhibiting ABCG2 in leukemia. Oncol Lett 12: 1051-1057, 2016.

12. Li JH, Zhang SQ, Qiu XG, Zhang SJ, Zheng SH and Zhang DH: Long non-coding RNA NEAT1 promotes malignant progression of thyroid carcinoma by regulating miRNA-214. Int J Oncol 50: 708-716, 2017.

13. Zhang H, Cai Y, Zheng L, Zhang Z, Lin X and Jiang N: Long noncoding RNA NEAT1 regulate papillary thyroid cancer progression by modulating miR-129-5p/KLK7 expression. J Cell Physiol 233: 6638-6648, 2018.

14. Hammond SM: An overview of microRNAs. Adv Drug Deliv Rev 87: 3-14, 2015.

15. Salmena L, Poliseno L, Tay Y, Kats L and Pandolfi PP: A ceRNA hypothesis: The Rosetta Stone of a hidden RNA language? Cell 146: 353-358, 2011.

16. Qi X, Zhang DH, Wu N, Xiao JH, Wang X and Ma W: ceRNA in cancer: Possible functions and clinical implications. J Med Genet 52: 710-718, 2015.

17. Livak KJ and Schmittgen TD: Analysis of relative gene expression data using real-time quantitative PCR and the 2(-Delta Delta C(T)) method. Methods 25: 402-408, 2001

18. Shaha AR: TNM classification of thyroid carcinoma. World J Surg 31: 879-887, 2007.

19. Barth S, Glick D and Macleod KF: Autophagy: Assays and artifacts. J Pthol 221: 117-124, 2010.

20. Han P, Li JW, Zhang BM, Lv JC, Li YM, Gu XY, Yu ZW, Jia YH, Bai XF, Li L and Cui BB: The lncRNA CRNDE promotes colorectal cancer cell proliferation and chemoresistance via miR-181a-5p-mediated regulation of $\mathrm{Wnt} / \beta$-catenin signaling. Mol Cancer 16: 9, 2017.

21. Gu P, Chen X, Xie R, Han J, Xie W, Wang B, Dong W, Chen C, Yang M, Jiang J, et al: IncRNA HOXD-AS1 regulates proliferation and chemo-resistance of castration-resistant prostate cancer via recruiting WDR5. Mol Ther 25: 1959-1973, 2017.

22. Yoshida K, Toden S, Ravindranathan P, Han H and Goel A: Curcumin sensitizes pancreatic cancer cells to gemcitabine by attenuating PRC2 subunit EZH2, and the lncRNA PVT1 expression. Carcinogenesis 38: 1036-1046, 2017.

23. Wang XM, Liu Y, Fan YX, Liu Z, Yuan QL, Jia M, Geng ZS, $\mathrm{Gu} \mathrm{L}$ and $\mathrm{Lu} \mathrm{XB}$ : LncRNA PTCSC3 affects drug resistance of anaplastic thyroid cancer through STAT3/INO80 pathway. Cancer Biol Ther 19: 590-597, 2018.

24. Liu F, Tai Y and Ma J: LncRNA NEAT1/let-7a-5p axis regulates the cisplatin resistance in nasopharyngeal carcinoma by targeting Rsf- 1 and modulating the Ras-MAPK pathway. Cancer Biol Ther 19: 534-542, 2018

25. Zhang J, Zhao B, Chen X, Wang Z, Xu H and Huang B: Silence of long noncoding RNA NEAT1 inhibits malignant biological behaviors and chemotherapy resistance in gastric cancer. Pathol Oncol Res 24: 109-113, 2018.

26. Jiang P, Wu X, Wang X, Huang W and Feng Q: NEAT1 upregulates EGCG-induced CTR1 to enhance cisplatin sensitivity in lung cancer cells. Oncotarget 7: 43337-43351, 2016.

27. Adriaens C, Standaert L, Barra J, Latil M, Verfaillie A, Kalev P, Boeckx B, Wijnhoven PW, Radaelli E, Vermi W, et al: p53 induces formation of NEAT1 lncRNA-containing paraspeckles that modulate replication stress response and chemosensitivity. Nat Med 22: 861-868, 2016
28. Parasramka M, Yan IK, Wang X, Nguyen P, Matsuda A, Maji S, Foye C, Asmann Y and Patel T: BAP1 dependent expression of long non-coding RNA NEAT-1 contributes to sensitivity to gemcitabine in cholangiocarcinoma. Mol Cancer 16: 22, 2017.

29. Xie Q, Lin S, Zheng M, Cai Q and Tu Y: Long noncoding RNA NEAT1 promoted the growth of cervical cancer cells via sponging miR-9-5p. Biochem Cell Biol 97: 100-108, 2018.

30. Lujambio A, Calin GA, Villanueva A, Ropero S, Sánchez-Céspedes M, Blanco D, Montuenga LM, Rossi S, Nicoloso MS, Faller WJ, et al: A microRNA DNA methylation signature for human cancer metastasis. Proc Natl Acad Sci USA 105: 13556-13561, 2008.

31. Gwak JM, Kim HJ, Kim EJ, Chung YR, Yun S, Seo AN, Lee HJ and Park SY: MicroRNA-9 is associated with epithelial-mesenchymal transition, breast cancer stem cell phenotype, and tumor progression in breast cancer. Breast Cancer Res Treat 147: 39-49, 2014.

32. Park YR, Lee ST, Kim SL, Liu YC, Lee MR, Shin JH, Seo SY, Kim SH, Kim IH, Lee SO and Kim SW: MicroRNA-9 suppresses cell migration and invasion through downregulation of TM4SF1 in colorectal cancer. Int J Oncol 48: 2135-2143, 2016.

33. Gomez GG, Volinia S, Croce CM, Zanca C, Li M, Emnett R, Gutmann DH, Brennan CW, Furnari FB and Cavenee WK: Suppression of microRNA-9 by mutant EGFR signaling upregulates FOXP1 to enhance glioblastoma tumorigenicity. Cancer Res 74: 1429-1439, 2014.

34. Zhao HM, Wei W, Sun YH, Gao JH, Wang Q and Zheng JH: MicroRNA-9 promotes tumorigenesis and mediates sensitivity to cisplatin in primary epithelial ovarian cancer cells. Tumour Biol 36: 6867-6873, 2015.

35. Pan Q, Sun L, Zheng D, Li N, Shi H, Song J, Shao G and Xu G: MicroRNA-9 enhanced cisplatin sensitivity in nonsmall cell lung cancer cells by regulating eukaryotic translation initiation factor 5A2. Biomed Res Int 2018: 1769040, 2018.

36. Munoz JL, Rodriguez-Cruz V, Ramkissoon SH, Ligon KL, Greco SJ and Rameshwar P: Temozolomide resistance in glioblastoma occurs by miRNA-9-targeted PTCH1, independent of sonic hedgehog level. Oncotarget 6: 1190-1201, 2015.

37. Guo F, Hou X and Sun Q: MicroRNA-9-5p functions as a tumor suppressor in papillary thyroid cancer via targeting BRAF. Oncol Lett 16: 6815-6821, 2018.

38. Zhang L, Yan L, Cao M, Zhang H, Li C, Bai Y, Yu P, Li M and Zhao X: SPAG9 promotes endometrial carcinoma cell invasion through regulation of genes related to the epithelial-mesenchymal transition. Eur J Gynaecol Oncol 37: 312-319, 2016.

39. Ren B, Wei X, Zou G, He J, Xu G, Xu F, Huang Y, Zhu H, Li Y, $\mathrm{Ma} \mathrm{G}$ and $\mathrm{Yu} \mathrm{P}$ : Cancer testis antigen SPAG9 is a promising marker for the diagnosis and treatment of lung cancer. Oncol Rep 35: 2599-2605, 2016.

40. Jagadish N, Gupta N, Agarwal S, Parashar D, Sharma A, Fatima R, Topno AP, Kumar V and Suri A: Sperm-associated antigen 9 (SPAG9) promotes the survival and tumor growth of triple-negative breast cancer cells. Tumour Biol 37: 13101-13110, 2016.

41. Ren B, Luo S, Xu F, Zou G, Xu G, He J, Huang Y, Zhu H and Li Y: The expression of DAMP proteins HSP70 and cancer-testis antigen SPAG9 in peripheral blood of patients with HCC and lung cancer. Cell Stress Chaperones 22: 237-244, 2017.

42. Zhen Z, Dong F, Shen H, Wang QG, Yang L and Hu J: MiR-524 inhibits cell proliferation and induces cell apoptosis in thyroid cancer via targeting SPAG9. Eur Rev Med Pharmacol Sci 22: 3812-3818, 2018

43. Yang C, Shen B, Zhang J and Zhang Q: Sperm-associated antigen 9 overexpression correlates with poor prognosis and insensitive to Taxol treatment in breast cancer. Biomarkers 21: 62-67, 2016.

This work is licensed under a Creative Commons Attribution-NonCommercial-NoDerivatives 4.0 International (CC BY-NC-ND 4.0) License. 